\title{
Analytical Evaluation of Ballasted Track Substructure Response under Repeated Train Loads
}

\author{
Piyush Punetha ${ }^{1}$, Sanjay Nimbalkar, ${ }^{\text {Ph.D MIEAust CPEng NER } 2 \square}{ }^{2}$, Hadi Khabbaz, ${ }^{\text {Ph.D.3 }}$
}

\begin{abstract}
The irrecoverable deformations in the substructure layers are detrimental to the
\end{abstract} track stability and demand frequent maintenance. With an escalation in axle-load and traffic volume, the frequency of maintenance operations has remarkably increased. Consequently, there is an inevitable need to predict the long-term behavior of the track substructure layers. This article presents a methodology to evaluate the recoverable and irrecoverable responses of the substructure layers under the train-induced repetitive loads. The present method utilizes an integrated approach combining track loading, resiliency and settlement models. The track substructure layers are simulated as lumped masses that are connected by springs and dashpots. The method is successfully validated against the field investigation data reported in the literature. A parametric study is conducted to investigate the influence of substructure layer properties on the track response. The results reveal that the response of each track layer is significantly influenced by the neighboring layer properties and the incorporation of multilayered track structure enables more accurate prediction of track behavior. The present analytical approach is simple, computationally efficient and may assist the practicing engineers in the safer design of the ballasted track.

Keywords: Railway track; Substructure; Mathematical model; Resiliency; Irrecoverable deformation.

\footnotetext{
${ }^{1} \mathrm{PhD}$ candidate, School of Civil and Environmental Engineering, FEIT, University of Technology Sydney, NSW2007, Australia. Email: Piyush.Punetha@student.uts.edu.au, ORCID: 0000-0002-0812-4708.

${ }^{2}$ Senior Lecturer, School of Civil and Environmental Engineering, FEIT, University of Technology Sydney, NSW-2007, Australia. Email: Sanjay.Nimbalkar@uts.edu.au, ORCID: 0000-0002-1538-3396.

${ }^{3}$ Associate Professor, School of Civil and Environmental Engineering, FEIT, University of Technology Sydney, NSW-2007, Australia. Email: Hadi.Khabbaz@uts.edu.au, ORCID: 0000-0001-6637-4601.

$\square$ Corresponding author
} 
The ballasted railway track is a complex engineering structure that consists of two primary components: substructure and superstructure. The substructure comprises of ballast, capping (subballast), structural fill, general fill and subgrade layers whose behavior governs the track performance and maintenance requirements (Selig and Waters 1994). These substructure layers undergo resilient (elastic) as well as irrecoverable deformation under the application of train induced repeated loads. The differential settlement produced due to non-uniform irrecoverable deformation in these layers is detrimental for track stability as it demands frequent maintenance cycles, increases the dynamic wheel-rail interactions and leads to poor riding quality (Esveld 2001).

A hike in traffic volume, speed and axle loads on railway tracks has increased the stresses and deformations in the substructure layers (Nimbalkar and Indraratna 2016; Priest et al. 2010). Consequently, the frequency of maintenance cycles has increased to meet this everincreasing demand. These maintenance operations require substantial financial investments due to the lack of proper planning and poor diagnosis of the track geometry degradation problems (Nguyen et al. 2016). Therefore, the accurate prediction of the behavior of individual track layers is imperative to plan and reduce the frequency of maintenance operations.

The field investigations are essential tools to understand the behavior of individual substructure layers and their mutual interaction. However, these studies are time-consuming and costly. The numerical and analytical approaches offer cost-effective alternatives to understand the behavior of the substructure layers. Several researchers have attempted to predict the track response using 2D (e.g. Kuo and Huang 2009; Yang et al. 2009), 2.5 D (e.g. Costa et al. 2010; Galvín et al. 2018; Hung et al. 2013; Yang and Hung 2001) and 3D finite element (FE) analyses (e.g. Banimahd et al. 2013; Bian et al. 2010; Chen and Zhou 2018; Connolly et al. 2013; Galvín et al. 2010; Hall 2003; Li et al. 2018; Sayeed and Shahin 2016; 
Shahu et al. 1999; Stewart and Selig 1982). Although the 2D models may be appropriate for predicting the static response of the track, these models cannot accurately simulate the threedimensional loading due to train-traffic (Powrie et al. 2007). On the other hand, 3D modelling of railway tracks using the FE method may be computationally intensive and time-consuming (Karlström and Boström 2006).

In contrast to FE analyses, analytical techniques are comparatively faster and may also facilitate the interpretation of results obtained from the FE analyses. Therefore, several analytical models have been developed to predict the behavior of the railway tracks under train induced repeated loading. These models range from a simple beam on elastic foundation (BoEF) approach (Esveld 2001) to advanced 3D vehicle-track coupled models (e.g. Guo and Zhai 2018; Zhai et al. 2009). Usually, the substructure in analytical models is either represented using equivalent springs and/or dashpots (Basu and Kameswara Rao 2013; Chen and Huang 2000), as a homogenous or multilayered half-space (Dieterman and Metrikine 1997; Kaynia et al. 2000; Metrikine and Popp 1999; Takemiya and Bian 2005) or a combination of multilayered half-space, springs and/or dashpots (Sheng et al. 1999). The representation of substructure as an equivalent spring may predict the overall track response, however, it neglects the mutual interaction between the substructure layers. A few researchers represented the ballast and/or capping layers as individual masses connected by springs and dashpots (Sun and Dhanasekar 2002; Zhai et al. 2004). Choudhury et al. (2008) employed a two-degree of freedom massspring-dashpot model to study the response of different subgrade soils below a railway track under cyclic loading condition. However, their approach neglected the role of capping in the track response and also ignored the continuity of the substructure layers along the longitudinal direction (i.e., the direction of train movement). Nevertheless, a limited number of approaches have captured the irrecoverable deformation in the individual substructure layers under traininduced repeated loads. 
This paper presents a methodology to evaluate both the resilient and irrecoverable responses of the track substructure layers under train-induced repetitive loads. The resilient response is evaluated by modelling the substructure layers as lumped masses connected by springs and dashpots. The irrecoverable response is evaluated using the empirical settlement models for ballast, capping and subgrade. The present model provides an insight into the deformation of the individual substructure layers, their mutual interaction and the influence of substructure layer properties on track response. The accuracy of the present method is validated by comparing the predicted results against the field investigation data reported in the literature. The present methodology is simple, computationally efficient and can readily be used to predict the cumulative track deformations. Consequently, the long term performance of the tracks can be evaluated.

\section{METHODOLOGY FOR PREDICTION OF TRACK SETTLEMENT}

The present study employs an integrated approach which combines three models as illustrated below:

- Track loading model: this model evaluates the train-induced repetitive loads that act on the top of the ballast layer.

- Track resiliency model: this model determines the resilient response of the track layers to the repeated train loading in terms of displacement, velocity and acceleration time histories.

- Track settlement model: this model evaluates the cumulative settlement in the substructure layers due to repeated passage of trains.

\section{Track loading model}

In the ballasted railway tracks, the train-induced repetitive loads are transferred to the substructure layers through the sleeper-ballast contact. The sleeper-ballast contact force at each 
sleeper location varies with time during the train passage. This force can be evaluated by using the beam on elastic foundation (BoEF) method. In this approach, the railway track is considered as a Euler-Bernoulli beam resting on an elastic foundation and the governing differential equation for the displacement of the beam is given by (Esveld 2001):

$$
E_{\mathrm{r}} I \frac{d^{4} \delta(x)}{d x^{4}}+k \delta(x)=0
$$

where $E_{\mathrm{r}}$ and $I$ are Young's modulus $\left(\mathrm{N} / \mathrm{m}^{2}\right)$ and the moment of inertia of the rail $\left(\mathrm{m}^{4}\right)$, respectively; $k$ denotes the track modulus $\left(\mathrm{N} / \mathrm{m}^{2}\right) ; \delta(x)$ is the vertical track deflection (m) at a distance ' $x$ ' (m) along the longitudinal direction as shown in Fig. 1. The vertical deflection due to a static wheel load $Q(\mathrm{~N})$ (located at $x=0$ ) can be evaluated by solving Eq. (1) under the boundary conditions $\delta(\infty)=0, \delta^{\prime}(0)=0$ and $\delta^{\prime \prime \prime}(0)=Q /\left(2 E_{\mathrm{r}} I\right)$ as:

$$
\delta(x)=\frac{Q}{2 k L} e^{-\left(\frac{x}{L}\right)}\left[\cos \left(\frac{x}{L}\right)+\sin \left(\frac{x}{L}\right)\right]
$$

where $L$ is the characteristic length (m) $\left[L=\left(4 E_{\mathrm{r}} I / k\right)^{1 / 4}\right]$. The term $k \delta(x)$ in Eq. (1) represents the reaction force per unit length provided by the track to the rail. Since the rail is supported at discrete locations by the sleepers, the reaction force provided by each rail seat (i.e., the rail seat load) can be calculated by multiplying $k \delta(x)$ with the sleeper spacing [S(m)].

As the beam on elastic foundation (BoEF) approach [Eq. (2)] considers the downward deflection to occur within a distance of $-3 \pi L / 4$ to $3 \pi L / 4$ from the point of load application (Esveld 2001), the rail seat load at a particular time instant due to a single wheel can be calculated for all sleepers lying within this range. Subsequently, the variation of rail seat load $\left[Q_{\mathrm{r}, \mathrm{n}}(t)\right]$ with time due to the cumulative train loading can be calculated using the superposition principle as:

$$
Q_{\mathrm{r}, \mathrm{n}}(t)=S k \sum_{j=1}^{a_{\mathrm{t}}} \delta\left(x_{\mathrm{nj}}, t\right)
$$


where $Q_{\mathrm{r}, \mathrm{n}}(t)$ is the total rail seat load (N) at $n^{\text {th }}$ sleeper at time $t$ (i.e. sleeper-ballast contact force); $a_{\mathrm{t}}$ denotes the total number of wheels/axles under consideration; $x_{\mathrm{nj}}$ is the distance (m) between the $n^{\text {th }}$ sleeper and $j^{\text {th }}$ wheel/axle. Fig. 1 illustrates an example to calculate the rail seat load-time history at a sleeper due to the passage of Thalys high-speed train travelling at a speed of $100 \mathrm{~km} / \mathrm{h}$. Thalys high-speed train operates on the European high-speed rail corridor with a maximum speed of $300 \mathrm{~km} / \mathrm{h}$. It is assumed that the rail and the wheels are free from defects and the subgrade is stiff. A stiff subgrade is usually characterized by a high value of elastic modulus (69-138 MPa) and high compressive strength (207-345 kPa) (Li et al. 2016).

Fig. 1(a) shows the configuration of the Thalys high-speed train. It comprises of two locomotives and eight carriages that are supported by two-axle bogies. The total number of axles on the train is 26. It is assumed that the train is moving in the positive $x$-direction. Referring to Fig. 1(b), at time instant $t_{1}$, the $n^{\text {th }}$ sleeper is at a distance of $x_{\mathrm{n} 1}\left(t_{1}\right)$ and $x_{\mathrm{n} 2}\left(t_{1}\right)$ from the leading $\left(Q_{1}\right)$ and trailing wheel $\left(Q_{2}\right)$, respectively. The distribution of rail deflection due to each wheel load, calculated using Eq. (2), is also shown in Fig. 1(b). It is apparent from the figure that the trailing wheel does not contribute to the deflection at the $n^{\text {th }}$ sleeper at time $t_{1}$, since $x_{\mathrm{n} 2}\left(t_{1}\right)$ is greater than $3 \pi L / 4$. As the train moves forward, the total deflection at the $n^{\text {th }}$ sleeper at time $t_{2}$ is the sum of deflection due to both the wheels [refer to Fig. 1(c)]. Similarly, the deflection due to other wheel loads can be calculated at each time instant. Subsequently, the rail seat load-time history is calculated using Eq. (3) at all the sleeper locations by applying a time shift according to the axle spacing and train speed. Fig. 1(d) shows the resulting railseat load time history at the $n^{\text {th }}$ and $n^{\text {th }}+1$ sleeper (i.e. next to $n^{\text {th }}$ sleeper) due to a single passage of Thalys train at a speed of $100 \mathrm{~km} / \mathrm{h}$. It can be observed that a time lag exists in the load time history for the $n^{\text {th }}+1$ sleeper. This time lag is equal to $S / V$, where, $V$ represents the train speed $(\mathrm{m} / \mathrm{s})$. 


\section{Track resiliency model}

The dynamic response of the railway track to train-induced repetitive loads is simulated using a three degree of freedom mass-spring-dashpot (3DoF MSD) model. Fig. 2 shows the MSD model for the dynamic analysis of the track. The track structure is assumed to be symmetric with respect to the track centerline. The ballast, capping, and subgrade layers are represented as lumped masses that are connected by springs and dashpots. The subgrade layer overlays the bedrock. The motion of the track layers is considered only in the vertical direction. The ballastcapping and capping-subgrade interfaces are assumed to be rigid, i.e., a no-slip condition exists for these interfaces. Zhai et al. (2004) used shear springs and dashpots between adjacent ballast masses to account for the continuity along the longitudinal direction. This approach of employing shear springs and dashpots has been extended to the capping and subgrade masses in the present method.

\section{Equations of motion}

Considering the dynamic equilibrium of the system below $n^{\text {th }}$ sleeper (refer to Fig. 2 ), the following system of equations can be derived using the D'Alembert's principle:

$$
\begin{aligned}
& m_{\mathrm{s}} \ddot{y}_{\mathrm{s}, \mathrm{n}}(t)+c_{\mathrm{s}} \dot{y}_{\mathrm{s}, \mathrm{n}}(t)+c_{\mathrm{c}}\left[\dot{y}_{\mathrm{s}, \mathrm{n}}(t)-\dot{y}_{\mathrm{c}, \mathrm{n}}(t)\right]+k_{\mathrm{s}} y_{\mathrm{s}, \mathrm{n}}(t)+k_{\mathrm{c}}\left[y_{\mathrm{s}, \mathrm{n}}(t)-y_{\mathrm{c}, \mathrm{n}}(t)\right] \\
& \quad+k_{\mathrm{s}}^{s}\left[2 y_{\mathrm{s}, \mathrm{n}}(t)-y_{\mathrm{s}, \mathrm{n}+1}(t)-y_{\mathrm{s}, \mathrm{n}-1}(t)\right]+c_{\mathrm{s}}^{s}\left[2 \dot{y}_{\mathrm{s}, \mathrm{n}}(t)-\dot{y}_{\mathrm{s}, \mathrm{n}+1}(t)-\dot{y}_{\mathrm{s}, \mathrm{n}-1}(t)\right]=f_{\mathrm{s}, \mathrm{n}}(t) \\
& m_{\mathrm{c}} \ddot{y}_{\mathrm{c}, \mathrm{n}}(t)+c_{\mathrm{c}}\left[\dot{y}_{\mathrm{c}, \mathrm{n}}(t)-\dot{y}_{\mathrm{s}, \mathrm{n}}(t)\right]+c_{\mathrm{b}}\left[\dot{y}_{\mathrm{c}, \mathrm{n}}(t)-\dot{y}_{\mathrm{b}, \mathrm{n}}(t)\right]+k_{\mathrm{c}}\left[y_{\mathrm{c}, \mathrm{n}}(t)-y_{\mathrm{s}, \mathrm{n}}(t)\right] \\
& \quad+k_{\mathrm{b}}\left[y_{\mathrm{c}, \mathrm{n}}(t)-y_{\mathrm{b}, \mathrm{n}}(t)\right]+k_{\mathrm{c}}^{s}\left[2 y_{\mathrm{c}, \mathrm{n}}(t)-y_{\mathrm{c}, \mathrm{n}+1}(t)-y_{\mathrm{c}, \mathrm{n}-1}(t)\right] \\
& \quad+c_{\mathrm{c}}^{s}\left[2 \dot{y}_{\mathrm{c}, \mathrm{n}}(t)-\dot{y}_{\mathrm{c}, \mathrm{n}+1}(t)-\dot{y}_{\mathrm{c}, \mathrm{n}-1}(t)\right]=f_{\mathrm{c}, \mathrm{n}}(t) \\
& m_{\mathrm{b}} \ddot{y}_{\mathrm{b}, \mathrm{n}}(t)+c_{\mathrm{b}}\left[\dot{y}_{\mathrm{b}, \mathrm{n}}(t)-\dot{y}_{\mathrm{c}, \mathrm{n}}(t)\right]+k_{\mathrm{b}}\left[y_{\mathrm{b}, \mathrm{n}}(t)-y_{\mathrm{c}, \mathrm{n}}(t)\right] \\
& \quad+k_{\mathrm{b}}^{s}\left[2 y_{\mathrm{b}, \mathrm{n}}(t)-y_{\mathrm{b}, \mathrm{n}+1}(t)-y_{\mathrm{b}, \mathrm{n}-1}(t)\right]+c_{\mathrm{b}}^{s}\left[2 \dot{y}_{\mathrm{b}, \mathrm{n}}(t)-\dot{y}_{\mathrm{b}, \mathrm{n}+1}(t)-\dot{y}_{\mathrm{b}, \mathrm{n}-1}(t)\right]=f_{\mathrm{b}, \mathrm{n}}(t)
\end{aligned}
$$

where the subscripts ' $b$ ', ' $c$ ' and ' $s$ ' denote the ballast, capping and subgrade layers, respectively; subscripts ' $\mathrm{n}$ ', ' $\mathrm{n}-1$ ' and ' $\mathrm{n}+1$ ' represent the $n^{\text {th }}$, previous and next to $n^{\text {th }}$ sleeper, respectively; $m, c$ and $k$ represent the vibrating mass $(\mathrm{kg})$, damping coefficient $(\mathrm{Ns} / \mathrm{m})$ and 


$$
\begin{gathered}
{\left[\begin{array}{ccc}
m_{\mathrm{s}} & 0 & 0 \\
0 & m_{\mathrm{c}} & 0 \\
0 & 0 & m_{\mathrm{b}}
\end{array}\right]\left\{\begin{array}{l}
\ddot{y}_{\mathrm{s}, \mathrm{n}}(t) \\
\ddot{y}_{\mathrm{c}, \mathrm{n}}(t) \\
\ddot{y}_{\mathrm{b}, \mathrm{n}}(t)
\end{array}\right\}+\left[\begin{array}{ccc}
c_{\mathrm{s}}+c_{\mathrm{c}}+2 c_{\mathrm{s}}^{s} & -c_{\mathrm{c}} & 0 \\
-c_{\mathrm{c}} & c_{\mathrm{c}}+c_{\mathrm{b}}+2 c_{\mathrm{c}}^{s} & -c_{\mathrm{b}} \\
0 & -c_{\mathrm{b}} & c_{\mathrm{b}}+2 c_{\mathrm{b}}^{s}
\end{array}\right]\left\{\begin{array}{l}
\dot{y}_{\mathrm{s}, \mathrm{n}}(t) \\
\dot{y}_{\mathrm{c}, \mathrm{n}}(t) \\
\dot{y}_{\mathrm{b}, \mathrm{n}}(t)
\end{array}\right\}} \\
+\left[\begin{array}{ccc}
k_{\mathrm{s}}+k_{\mathrm{c}}+2 k_{\mathrm{s}}^{s} & -k_{\mathrm{c}} & 0 \\
-k_{\mathrm{c}} & k_{\mathrm{c}}+k_{\mathrm{b}}+2 k_{\mathrm{c}}^{s} & -k_{\mathrm{b}} \\
0 & -k_{\mathrm{b}} & k_{\mathrm{b}}+2 k_{\mathrm{b}}^{s}
\end{array}\right]\left\{\begin{array}{l}
y_{\mathrm{s}, \mathrm{n}}(t) \\
y_{\mathrm{c}, \mathrm{n}}(t) \\
y_{\mathrm{b}, \mathrm{n}}(t)
\end{array}\right\}=\left\{\begin{array}{l}
f_{\mathrm{s}, \mathrm{n}}(t) \\
f_{\mathrm{c}, \mathrm{n}}(t) \\
f_{\mathrm{b}, \mathrm{n}}(t)
\end{array}\right\} \\
+\left[\begin{array}{ccc}
c_{\mathrm{s}}^{s} & 0 & 0 \\
0 & c_{\mathrm{c}}^{s} & 0 \\
0 & 0 & c_{\mathrm{b}}^{s}
\end{array}\right]\left\{\begin{array}{l}
\dot{y}_{\mathrm{s}, \mathrm{n}+1}(t)+\dot{y}_{\mathrm{s}, \mathrm{n}-1}(t) \\
\dot{y}_{\mathrm{c}, \mathrm{n}+1}(t)+\dot{y}_{\mathrm{c}, \mathrm{n}-1}(t) \\
\dot{y}_{\mathrm{b}, \mathrm{n}+1}(t)+\dot{y}_{\mathrm{b}, \mathrm{n}-1}(t)
\end{array}\right\}+\left[\begin{array}{ccc}
k_{\mathrm{s}}^{s} & 0 & 0 \\
0 & k_{\mathrm{c}}^{s} & 0 \\
0 & 0 & k_{\mathrm{b}}^{s}
\end{array}\right]\left\{\begin{array}{l}
y_{\mathrm{s}, \mathrm{n}+1}(t)+y_{\mathrm{s}, \mathrm{n}-1}(t) \\
y_{\mathrm{c}, \mathrm{n}+1}(t)+y_{\mathrm{c}, \mathrm{n}-1}(t) \\
y_{\mathrm{b}, \mathrm{n}+1}(t)+y_{\mathrm{b}, \mathrm{n}-1}(t)
\end{array}\right\}
\end{gathered}
$$

stiffness $(\mathrm{N} / \mathrm{m})$, respectively; $k^{s}$ and $c^{s}$ are the shear stiffness $(\mathrm{N} / \mathrm{m})$ and shear damping coefficients $(\mathrm{Ns} / \mathrm{m}) ; f(t), \ddot{y}(t), \dot{y}(t)$ and $y(t)$ denote the external force $(\mathrm{N})$, vertical acceleration $\left(\mathrm{m} / \mathrm{s}^{2}\right)$, velocity $(\mathrm{m} / \mathrm{s})$ and displacement $(\mathrm{m})$, respectively. Eqs. [4(a-c)] can be further simplified as:

Eq. (5) is solved using the Newmark's- $\beta$ numerical integration scheme. The solution of the equation gives the transient displacement, velocity and acceleration response for the ballast, capping and subgrade layers. The time step in the present study is chosen as $1 \times 10^{-4} \mathrm{~s}$ to achieve the desired accuracy.

\section{Determination of model parameters}

The input parameters include the mass, stiffness and damping coefficient of the ballast, capping and subgrade layers. To determine these parameters, a pyramidal distribution of vertical load from the sleeper to the substructure layers is assumed (Ahlbeck et al. 1975), which was found to be in close agreement with the field measurements (Zhang et al. 2016). In this model, the vertical stresses in the substructure layers are uniformly distributed within the pyramid and zero outside the pyramid. Thus, the portion inside the load distribution pyramid can be considered as the effective region of ballast, capping and subgrade in the dynamic analysis. Consequently, the mass and stiffness of the effective regions of substructure layers below each sleeper can be determined using the geometry of the pyramid as: 


$$
\begin{gathered}
m_{\mathrm{b}}=\rho_{\mathrm{b}} h_{\mathrm{b}}\left[l_{\mathrm{e}} b_{\mathrm{sl}}+\left(l_{\mathrm{e}}+b_{\mathrm{sl}}\right) h_{\mathrm{b}} \tan \alpha+\frac{4}{3} h_{\mathrm{b}}^{2} \tan ^{2} \alpha\right] \\
m_{\mathrm{c}}=\rho_{\mathrm{c}} h_{c}\left[l_{\mathrm{e}} b_{\mathrm{sl}}+\left(l_{\mathrm{e}}+b_{\mathrm{sl}}\right)\left(2 h_{\mathrm{b}} \tan \alpha+h_{\mathrm{c}} \tan \beta\right)+4 h_{\mathrm{b}} \tan \alpha\left(h_{\mathrm{b}} \tan \alpha+h_{\mathrm{c}} \tan \beta\right)\right. \\
\left.+\frac{4}{3} h_{\mathrm{c}}^{2} \tan ^{2} \beta\right] \\
m_{\mathrm{s}}=\rho_{\mathrm{s}} h_{\mathrm{s}}\left[l_{\mathrm{e}} b_{\mathrm{sl}}+\left(l_{\mathrm{e}}+b_{\mathrm{sl}}\right)\left(2 h_{\mathrm{b}} \tan \alpha+2 h_{\mathrm{c}} \tan \beta+h_{\mathrm{s}} \tan \gamma\right)+4\left(h_{\mathrm{b}} \tan \alpha+h_{\mathrm{c}} \tan \beta\right)\left(h_{\mathrm{b}} \tan \alpha\right.\right. \\
\left.\left.+h_{\mathrm{c}} \tan \beta+h_{\mathrm{s}} \tan \gamma\right)+\frac{4}{3} h_{\mathrm{s}}^{2} \tan ^{2} \gamma\right] \\
k_{\mathrm{b}}=\frac{2\left(l_{\mathrm{e}}-b_{\mathrm{sl}}\right) \tan \alpha}{\ln \left(\frac{l_{\mathrm{e}}}{b_{\mathrm{sl}}} \cdot \frac{b_{\mathrm{sl}}+2 h_{\mathrm{b}} \tan \alpha}{l_{\mathrm{e}}+2 h_{\mathrm{b}} \tan \alpha}\right)} E_{\mathrm{b}} \\
k_{\mathrm{s}}=\frac{2\left(l_{\mathrm{e}}-b_{\mathrm{sl}}\right) \tan \beta}{\ln \left(\frac{l_{\mathrm{e}}+2 h_{\mathrm{b}} \tan \alpha+2 h_{\mathrm{c}} \tan \beta}{b_{\mathrm{sl}}+2 h_{\mathrm{b}} \tan \alpha+2 h_{\mathrm{c}} \tan \beta} \cdot \frac{b_{\mathrm{sl}}+2 h_{\mathrm{b}} \tan \alpha+2 h_{\mathrm{c}} \tan \beta+2 h_{\mathrm{s}} \tan \gamma}{l_{\mathrm{e}}+2 h_{\mathrm{b}} \tan \alpha+2 h_{\mathrm{c}} \tan \beta+2 h_{\mathrm{s}} \tan \gamma}\right)} E_{\mathrm{s}}
\end{gathered}
$$

where the subscripts 'b', 'c' and 's' denote the ballast, capping and subgrade layers, respectively; $\rho, E$ and $h$ represent the density $\left(\mathrm{kg} / \mathrm{m}^{3}\right)$, elastic modulus $\left(\mathrm{N} / \mathrm{m}^{2}\right)$ and thickness $(\mathrm{m})$, respectively; $l_{\mathrm{e}}$ and $b_{\mathrm{sl}}$ are the effective length (m) and width (m) of sleeper, respectively $\left(l_{\mathrm{e}}=l_{\mathrm{sl}}-g_{\mathrm{t}}\right) ; l_{\mathrm{sl}}$ is sleeper length $(\mathrm{m}) ; g_{\mathrm{t}}$ is the center to center distance between the rails $(\mathrm{m}) ; \alpha, \beta$ and $\gamma$ are the stress distribution angles $\left(^{\circ}\right)$ of ballast, capping and subgrade layers, respectively. The detailed derivation of Eqs. (6-11) is provided in Appendix II.

The stress distribution angle (i.e., inclination angle of the pyramid with vertical) can be evaluated using Burmister's theory of stress distribution in layered soil (Burmister 1958; Giroud and Han 2004):

$$
\tan \alpha=\tan \alpha_{0}\left[1+0.204\left(\frac{E_{\mathrm{b}}}{E_{\mathrm{c}}}-1\right)\right] ; \tan \beta=\tan \beta_{0}\left[1+0.204\left(\frac{E_{\mathrm{c}}}{E_{\mathrm{s}}}-1\right)\right]
$$

where $\alpha_{0}$ and $\beta_{0}$ are the reference stress distribution angles in uniform ballast (i.e., for $E_{\mathrm{b}}=E_{\mathrm{c}}$ ) and capping (i.e., for $E_{\mathrm{c}}=E_{\mathrm{s}}$ ), respectively. The value of $\alpha_{0}$ is $45^{\circ}$ (Zhang et al. 2016). The 
value of $\beta_{0}$ is considered as $27^{\circ}$ based on the assumed stress distribution of 2:1 (Han et al. 2013).

It is interesting to note that the load distribution pyramids below adjacent sleepers might overlap in the longitudinal direction in case of large thickness, small sleeper spacing and high stress distribution angle (Zhai et al. 2004). Figs. 3(a), 3(b) and 3(c) show the overlapping in the pyramids along the longitudinal direction in the ballast, capping and subgrade layers, respectively. The height of the overlapped regions can be evaluated as:

$$
\begin{gathered}
h_{\mathrm{bl}}=h_{\mathrm{b}}-\left(\frac{S-b_{\mathrm{sl}}}{2 \tan \alpha}\right) \\
h_{\mathrm{cl}}=h_{\mathrm{c}}-\left(\frac{S-b_{\mathrm{sl}}-2 h_{\mathrm{b}} \tan \alpha}{2 \tan \beta}\right) \\
h_{\mathrm{sl}}=h_{\mathrm{s}}-\left(\frac{S-b_{\mathrm{sl}}-2 h_{\mathrm{b}} \tan \alpha-2 h_{\mathrm{c}} \tan \beta}{2 \tan \gamma}\right)
\end{gathered}
$$

where $h_{\mathrm{bl}}, h_{\mathrm{cl}}$ and $h_{\mathrm{sl}}$ are the overlap height (m) in ballast, capping and subgrade along the longitudinal direction, respectively. The established pyramidal load distribution model only considers the overlapping along the longitudinal direction (Zhai et al. 2004). However, the load distribution pyramids may also overlap along the transverse direction (perpendicular to the direction of train movement) if the layer thickness and stress-distribution angles are high, and the sleeper length is small. Figs. 3(d), 3(e) and 3(f) show the overlapping along the transverse directions in ballast, capping and subgrade, respectively. The overlap height in the ballast, capping and subgrade along the transverse direction can be determined as:

$$
\begin{gathered}
h_{\mathrm{bt}}=h_{\mathrm{b}}-\left(\frac{l_{\mathrm{sl}}-2 l_{\mathrm{e}}}{2 \tan \alpha}\right) \\
h_{\mathrm{ct}}=h_{\mathrm{c}}-\left(\frac{l_{\mathrm{sl}}-2 l_{\mathrm{e}}-2 h_{\mathrm{b}} \tan \alpha}{2 \tan \beta}\right) \\
h_{\mathrm{st}}=h_{\mathrm{s}}-\left(\frac{l_{\mathrm{sl}}-2 l_{\mathrm{e}}-2 h_{\mathrm{b}} \tan \alpha-2 h_{\mathrm{c}} \tan \beta}{2 \tan \gamma}\right)
\end{gathered}
$$


where $h_{\mathrm{bt}}, h_{\mathrm{ct}}$ and $h_{\mathrm{st}}$ are the overlap height (m) in ballast, capping and subgrade along the transverse direction, respectively. Fig. 4 shows the effective portion of the substructure layers below each sleeper point considered in the analysis. The geometry of this effective portion (consequently, the vibrating mass and stiffness of substructure layers) varies depending on the overlapping within the substructure layers. It is apparent from Fig. 4 that the stiffness and vibrating mass of the substructure layers may be over-predicted if the overlapping along the transverse direction is neglected in the analysis. Therefore, the mass and stiffness of the substructure layers can be determined more accurately if the overlapping is also considered along the transverse direction.

In summary, the overlap height is first calculated using Eqs. 13-18 and the resulting geometry of the load distribution pyramid is identified. Subsequently, the vibrating mass and stiffness of the substructure layers (effective region) is determined using a similar procedure as described in APPENDIX II. Thus, the effect of overlapping is accounted for in the analysis by modifying the vibrating mass and stiffness of the substructure layers. Nevertheless, a detailed description of the different cases (or geometries) that may arise due to overlapping, and the corresponding equations to evaluate the mass and stiffness of the substructure layers for each case will be provided by the authors upon request.

The equivalent damping coefficient of the substructure layers can be calculated as (Nimbalkar et al. 2012):

$$
c_{\mathrm{s}}=\sqrt{\frac{E_{\mathrm{s}} \rho_{\mathrm{s}}}{\left(1+v_{\mathrm{s}}\right)\left(1-v_{\mathrm{s}}\right)}} ; c_{\mathrm{c}}=\sqrt{\frac{E_{\mathrm{c}} \rho_{\mathrm{c}}}{\left(1+v_{\mathrm{c}}\right)\left(1-v_{\mathrm{c}}\right)}} ; c_{\mathrm{b}}=\sqrt{\frac{E_{\mathrm{b}} \rho_{\mathrm{b}}}{\left(1+v_{\mathrm{b}}\right)\left(1-v_{\mathrm{b}}\right)}}
$$

where $v_{\mathrm{s}}, v_{\mathrm{c}}$ and $v_{\mathrm{b}}$ are the Poisson's ratios of subgrade, capping and ballast layers, respectively. The external force $f_{\mathrm{b}, \mathrm{n}}(t)$ in Eq. (5) is equal to the load-time history calculated using the loading model, while the external forces $f_{\mathrm{s}, \mathrm{n}}(t)$ and $f_{\mathrm{c}, \mathrm{n}}(t)$ are considered as zero. The input parameters to evaluate the load-time history include $E_{\mathrm{r}}, I, S, Q$ and $k$. The parameters $E_{\mathrm{r}}, I$ and $S$ are usually 
pre-defined. The wheel load is one half of the axle load $\left(Q_{\mathrm{a}}\right)$. To account for the dynamic effects due to the wheel-rail irregularities, the wheel load can also be multiplied by the dynamic amplification factor (DAF). In the present study, DAF is evaluated using the method developed by Nimbalkar and Indraratna (2016):

$$
D A F=1+i_{1}\left(\frac{V}{D_{w}}\right)^{i_{2}}
$$

where $V$ is the train speed (in $\mathrm{km} / \mathrm{h}$ ); $D_{\mathrm{w}}$ is the wheel diameter (in $\mathrm{m}$ ); $i_{1}$ and $i_{2}$ are the empirical parameters that depend on the axle load and subgrade type. This method was derived from the field investigations, and it accounts for the variation in load amplification due to a change in subgrade type, axle load and train speed. The value of parameters $i_{1}$ and $i_{2}$ may range between 0.0052 to 0.0065 and 0.75 to 1.02 , respectively, depending on the subgrade type and axle load (Nimbalkar and Indraratna 2016).

The track modulus is calculated by modifying the approach described in Doyle (1980):

$$
\frac{1}{k}=S\left(\frac{1}{k_{\mathrm{p}}}+\frac{1}{k_{\mathrm{b}}}+\frac{1}{k_{\mathrm{c}}}+\frac{1}{k_{\mathrm{s}}}\right)
$$

where $k_{\mathrm{p}}$ is the spring constant of rail pad ( $\left.\mathrm{N} / \mathrm{m}\right)$ (including sleeper).

\section{Track settlement model}

The cumulative settlement (or irrecoverable deformation) in the substructure layers has been predicted using the empirical models.

\section{Settlement in granular (ballast and capping) layers}

The irrecoverable deformation in ballast and capping has been calculated using a power model (Punetha et al. 2019):

$$
\varepsilon_{\mathrm{b}}^{p}=k_{1}^{b}\left(\frac{\sigma_{\mathrm{oct}}}{P_{\mathrm{atm}}}\right)^{k_{2}^{b}}\left(\frac{\tau_{\mathrm{oct}}}{P_{\mathrm{atm}}}\right)^{k_{3}^{b}} N^{k_{4}^{b}}
$$




$$
\varepsilon_{\mathrm{c}}^{p}=k_{1}^{c}\left(\frac{\sigma_{\mathrm{oct}}}{P_{\mathrm{atm}}}\right)^{k_{2}^{c}}\left(\frac{\tau_{\mathrm{oct}}}{P_{\mathrm{atm}}}\right)^{k_{3}^{c}} N^{k_{4}^{c}}
$$

where the superscripts ' $b$ ' and ' $c$ ' denote the ballast and capping layer, respectively; $k_{1}, k_{2}, k_{3}$ and $k_{4}$ are the empirical parameters; $\varepsilon_{\mathrm{b}}{ }^{p}$ and $\varepsilon_{\mathrm{c}}{ }^{p}$ are the irrecoverable strains (\%) in vertical direction in ballast and capping, respectively; $\sigma_{\text {oct }}$ and $\tau_{\text {oct }}$ are the octahedral normal and shear stresses $\left(\mathrm{N} / \mathrm{m}^{2}\right)$, respectively; $P_{\text {atm }}$ is the atmospheric pressure $\left(\mathrm{N} / \mathrm{m}^{2}\right) ; N$ is the number of load cycles. The parameters $k_{1}, k_{2}$ and $k_{3}$ represent the influence of the infill type, octahedral normal and shear stresses on the magnitude of $\varepsilon_{\mathrm{b}}{ }^{p}\left(\right.$ or $\varepsilon_{\mathrm{c}}{ }^{p}$ ) corresponding to the first load cycle. The parameter $k_{4}$ governs the variation of $\varepsilon_{\mathrm{b}}{ }^{p}$ ( or $\varepsilon_{\mathrm{c}}{ }^{p}$ ) with the number of load cycles. The parameters $k_{1}, k_{2}, k_{3}$ and $k_{4}$ can be evaluated by fitting the experimental curves of $\varepsilon_{\mathrm{b}}{ }^{p}$ or $\varepsilon_{\mathrm{c}}{ }^{p}$ with $N$ at different loading conditions. The total settlement can be evaluated by multiplying the strain with the thickness of the ballast and capping layers.

\section{Settlement in subgrade layers}

The model developed by Li and Selig (1996) has been used to predict the irrecoverable deformation in the subgrade layer:

$$
\varepsilon_{\mathrm{s}}^{p}=a\left(\frac{\sigma_{\mathrm{d}}^{\prime}}{\sigma_{\mathrm{s}}}\right)^{m} N^{b}
$$

where $\varepsilon_{\mathrm{s}}^{p}$ is the cumulative plastic strain in subgrade $(\%) ; \sigma_{\mathrm{d}}^{\prime}$ is the deviator stress $\left(\mathrm{N} / \mathrm{m}^{2}\right) ; \sigma_{\mathrm{s}}$ is the compressive strength of subgrade soil $\left(\mathrm{N} / \mathrm{m}^{2}\right) ; a, m$ and $b$ are the parameters that depend on the subgrade soil type. Table 1 shows the values of these parameters for different subgrade soil type. The subgrade is assumed to be divided into 10 layers and the strain in each layer is evaluated using Eq. (24). Subsequently, the total irrecoverable deformation $\left(s_{\mathrm{s}}\right)$ is calculated as: 


$$
s_{\mathrm{s}}=\sum_{i=1}^{10}\left(\varepsilon_{\mathrm{s}}^{p}\right)_{\mathrm{i}} h_{\mathrm{i}}
$$

where $h_{\mathrm{i}}$ is the thickness of $i^{\text {th }}$ subgrade layer $(\mathrm{m}) ;\left(\varepsilon_{\mathrm{s}}{ }^{p}\right)_{\mathrm{i}}$ is the cumulative plastic strain in the $i^{\text {th }}$ subgrade layer. The irrecoverable deformation is calculated after the completion of an individual load cycle. This cumulative approach is better than the calculation of irrecoverable deformation during an individual cycle, as the later approach would incur a huge amount of computational time (Suiker and De Borst 2003). The stresses in the substructure layers are calculated using the method described in Appendix I.

\section{MODEL VALIDATION}

The present method can be used to predict the resilient as well as the irrecoverable response of the ballasted railway tracks under train induced repeated loading. The response includes the resilient displacement, velocity and acceleration, and irrecoverable displacement of the substructure layers. The substructure layer response predicted using the present method is compared with the field investigation data reported by Takemiya and Bian (2005), Gräbe et al. (2005), Gräbe and Shaw (2010), Priest et al. (2010) and Mishra et al. (2014).

Takemiya and Bian (2005) reported the ground displacement and acceleration recorded during the passage of the Swedish X-2000 train at a speed of $70 \mathrm{~km} / \mathrm{h}$ and $200 \mathrm{~km} / \mathrm{h}$. The track was located over very soft ground at the West Coast line in Sweden. Table 2 shows the values of the parameters used in the analysis. The ballast layer is replaced by an equivalent top soil layer in the analysis to ensure consistency with the approach used by Takemiya and Bian (2005). The train is initially at a distance of $3 \pi L / 4$ from the first sleeper and is assumed to travel in the positive $x$-direction (i.e. from left to right). A total of 25 sleepers are considered in the analysis to ensure accurate prediction of deformations and the results are reported for the central sleeper (i.e. $13^{\text {th }}$ sleeper). Fig. 5 compares the vertical displacement and vertical acceleration time histories computed using the present method with the data measured from 
field investigations. It can be observed that the ground displacement calculated using the present method is in good agreement with the field data at a train speed of $70 \mathrm{~km} / \mathrm{h}$. For 200 $\mathrm{km} / \mathrm{h}$, the vertical displacement in the downward direction is nearly identical to the field observation. However, a little discrepancy exists in the predictions corresponding to $200 \mathrm{~km} / \mathrm{h}$ as the field data also showed vertical displacement in the upward direction, which is absent in the model predictions. The accelerations predicted using the present method show a similar trend as the field data for both $70 \mathrm{~km} / \mathrm{h}$ and $200 \mathrm{~km} / \mathrm{h}$, however, the peak values are underestimated.

Gräbe et al. (2005) conducted field investigations in a heavy haul track at Bloubank site in the Broodsnyersplaas-Richards Bay Coal Export Line, South Africa. The track comprises of a $300 \mathrm{~mm}$ thick ballast layer overlying the formation, which constitutes of four layers of selected high-quality material (each $200 \mathrm{~mm}$ thick) and the in-situ material (weathered tillite). The instrumentation included Multi-depth deflectometers (MDDs), pressure plates, LVDT's, accelerometers and strain gauges. These instruments were used to monitor the layer deformation (resilient and permanent), vertical stresses in substructure layers, rail and sleeper displacement, wheel load, lateral force, sleeper reaction and acceleration in rail, sleeper and ballast. Table 2 shows the values of the parameters used in the model predictions. Table 3 compares the resilient settlement and vertical stress calculated using the present method with field data. It can be observed that the model predictions are consistent with field investigations. The present method slightly under-predicts the magnitude of vertical stress just below the ballast layer ( $0 \mathrm{~mm}$ below the foundation). Gräbe and Shaw (2010) reported the variation of irrecoverable/ permanent settlement of the substructure layers below the ballast with tonnage in million gross tonnes (MGT) at the same site. Fig. 6 compares the irrecoverable deformation calculated using the present method with that reported by Gräbe and Shaw (2010). It can be 
observed that the predicted results are in good agreement with the data measured from field investigations.

Priest et al. (2010) also conducted field investigations at the Bloubank site in the Broodsnyersplaas-Richards Bay Coal Export Line, South Africa. The instrumentation included geophones to measure the velocity in substructure layers (which was used to back-calculate the displacement), and a combination of remote video monitoring and particle image velocimetry to measure the sleeper displacement. Table 2 shows the parameters used to predict the response of the substructure layers. Fig. 7(a) compares the variation of the resilient deformation with time due to the passage of 26-tonne axle load coal wagons, predicted using the present method with that recorded in the field experiments. It can be observed that the predicted response is in good agreement with the field data. Fig. 7(b) shows the variation of resilient displacement with time at different depth below the sleeper due to the passage of two adjacent bogies ( 4 axles). It can be observed that the predicted results are consistent with the field data. The resilient displacement decreases with depth, and the influence of the individual axles in the response diminishes with depth.

The four $200 \mathrm{~mm}$ thick layers of selected high-quality material were replaced by a single capping layer ( $800 \mathrm{~mm}$ thick) with equivalent elastic modulus in the analysis. Therefore, the results are only available for the top of the ballast layer $(0 \mathrm{~m})$, bottom of the ballast layer $(0.3 \mathrm{~m})$ and bottom of the capping layer $(1.1 \mathrm{~m})$. Fig. $7(\mathrm{c})$ compares the variation of the resilient deformation with time due to the passage of 20-tonne axle load coal wagons, predicted using the present method with the field data. It can be observed that the predicted results are in good agreement with the field observations. Fig. 7(d) shows the increase in vertical stress at $800 \mathrm{~mm}$ below the bottom of the sleeper predicted using the present method and that using the FE analysis by Priest et al. (2010). It can be observed that the predictions using the present method are consistent with that reported by Priest et al. (2010). 

the Amtrak's North East Corridor in the USA. The instrumentation included MDDs to monitor

the deformation of the substructure layers and strain gauges to monitor the wheel load and sleeper reactions. Table 2 shows the parameters used for the prediction of the track response. Fig. 8 compares the resilient deformation in the ballast layer due to the passage of Acela express train predicted using the present method with the field measurements. It can be observed that the predicted trend is consistent with the field data. The small discrepancy in the peak values is likely due to a slight difference in the actual and the predicted load-time history.

Thus, the proposed method in this study can predict the stresses, resilient and irrecoverable response of the track substructure layers with adequate accuracy. The method is simple and computationally efficient. It can serve as a tool to optimize the track performance by selecting the best possible combination of geomaterials in the substructure layers. The method can capture the irrecoverable deformation of the substructure layers and hence, predict the long-term performance of the track, which can be used to design and optimize the maintenance cycles.

\section{RESULTS AND DISCUSSION}

A parametric study is conducted to investigate the influence of thickness and elastic modulus of the substructure layers on the track performance. Table 2 provides the range of the substructure parameters considered in the analysis. The nominal values of the parameters are shown in the parenthesis. The results are calculated for the passage of Thalys high-speed train at a speed of $100 \mathrm{~km} / \mathrm{h}$. In each analysis, the value of one parameter is varied at a time while the other parameters are assigned the nominal values. 


\section{Influence of layer thickness}

Fig. 9(a) illustrates the influence of thickness on the average irrecoverable strain accumulated in the substructure layers when the track is subjected to tonnage of 100 MGT. The average irrecoverable strain is the ratio of vertical irrecoverable deformation in a layer to its initial thickness. It can be observed from the figure that the average irrecoverable strain in the ballast, capping and subgrade layers decreases by 22,47 and $31 \%$, respectively, with an increase in ballast thickness $\left(h_{\mathrm{b}}\right)$ from 0.15 to $0.6 \mathrm{~m}$. It is interesting to note that a $31 \%$ reduction in the subgrade strain, in this case, represents a decrease in the permanent subgrade settlement by 10 $\mathrm{mm}$. This decrease in strain results from a combination of two counteracting effects. First, an increase in granular layer thickness increases the track modulus (and consequently, the rail seat load), which increases the stresses in substructure layers (Li et al. 2016). Second, an increase in $h_{\mathrm{b}}$ enhances the stress spreading ability of ballast and increases the depth of substructure layers from sleeper bottom, which decreases the stress (Li and Selig 1998). It is apparent that the second effect is dominant in this case, as there is an overall reduction in strain.

The average irrecoverable strain in capping and subgrade decreases by 76 and $29 \%$, respectively, with an increase in capping thickness $\left(h_{\mathrm{c}}\right)$ from 0.15 to $0.45 \mathrm{~m}$. However, the ballast strain increases by $1.6 \%$ with an increase in $h_{\mathrm{c}}$. This increment is due to a rise in ballast stress with an increase in $h_{\mathrm{c}}$ for a fixed value of $h_{\mathrm{b}}$. The increase in stress is reasonable since the second effect mentioned above is negligible for this case. The subgrade thickness $\left(h_{\mathrm{s}}\right)$ also influences the strain in the substructure layers. The average irrecoverable strain in ballast, capping and subgrade decreases by 19, 27 and 87\%, respectively, with an increase in $h_{\mathrm{s}}$ from 1 to $10 \mathrm{~m}$. This strain reduction in ballast and capping is due to a decrease in the stresses in the granular layers with an increase in $h_{\mathrm{s}}$. Since, the track modulus decreases with an increase in $h_{\mathrm{s}}$ (Li et al. 2016), the rail seat load decreases and consequently, the stresses in the track layers 
reduce. The average subgrade strain also decreases with an increase in $h_{\mathrm{s}}$. This is reasonable since the contribution of the deep subgrade layers to the total subgrade settlement is minimal. Thus, it is apparent that the thickness of the substructure layers significantly influences the irrecoverable deformation response of the track substructure.

\section{Influence of elastic modulus}

Fig. 9(b) shows the variation of average irrecoverable strain accumulated in the substructure layers with the elastic modulus when the track is subjected to tonnage of 100 MGT. It can be observed that the average irrecoverable strain in ballast, capping and subgrade decreases by 9.3, 2.3 and 9\%, respectively, with an increase in ballast modulus $\left(E_{\mathrm{b}}\right)$ from 138 to $551 \mathrm{MPa}$. The increase in $E_{\mathrm{b}}$ leads to an increment in the track modulus, which increases the rail seat load (Selig and Waters 1994). Consequently, the stress in the substructure layers must increase with an increase in $E_{\mathrm{b}}$. However, a stiff ballast layer (with large $E_{\mathrm{b}}$ ) distributes the load to a wider area of capping as compared to less stiff ballast layer. Therefore, the actual magnitude of the stress depends on the degree of increment of both rail seat load and the load distribution zone/area. In this case, the strain decreases, which implies that the increment in load distribution area dominates the response.

The average irrecoverable strain in capping and subgrade decreases by 30 and $3.5 \%$ with an increase in capping modulus $\left(E_{\mathrm{c}}\right)$ from 69 to $276 \mathrm{MPa}$. However, the ballast strain increases by $9.8 \%$ with an increase in $E_{\mathrm{c}}$. The increase in ballast strain may be ascribed to a reduction in the load spread area with an increase in $E_{\mathrm{c}}$. Burmister (1958) showed that the vertical stress at the interface of a two-layer medium increases with a reduction in the ratio of modulus of upper to lower layer materials. In the present study, this increase in vertical stress (due to a reduction in $E_{\mathrm{b}} / E_{\mathrm{c}}$ ratio) is manifested by a corresponding decrease in $\alpha$. Consequently, the stress and the associated strain in the ballast layer increases with an increase 
in $E_{\mathrm{c}}$. Nevertheless, $\beta$ increases with an increase in $E_{\mathrm{c}}$ and therefore, the stress and the associated strain in the capping and subgrade layers decreases.

It is apparent from Fig. 9(b) that $E_{\mathrm{s}}$ plays a significant role in the irrecoverable response of the substructure. The average irrecoverable strain in the ballast and capping layers increases by 51 and $104 \%$ with an increase in $E_{\mathrm{s}}$ from 14 to $276 \mathrm{MPa}$, respectively. However, the subgrade strain decreases by $99 \%$ with an increase in $E_{\mathrm{s}}$. An increment in $E_{\mathrm{s}}$ increases the track modulus and the rail seat load ( $\mathrm{Li}$ et al. 2016). Thus, the stresses in the substructure layers increase with an increase in $E_{\mathrm{s}}$. Consequently, the ballast and capping strain increases. However, in the subgrade, the increase in stress is compensated by a corresponding increase in the strength with an increment in $E_{\mathrm{s}}$ ( $\mathrm{Li}$ et al. 2016). Therefore, the subgrade settlement decreases with an increase in $E_{\mathrm{s}}$.

Thus, the present method can accurately predict the variation in the irrecoverable deformation of the track layers in response to the track parameters. This method may help the practicing engineers to evaluate the magnitude of track substructure settlement after the completion of a fixed number of load cycles (or tonnage). This may aid in the adequate planning of the maintenance cycles by predicting the time when the substructure settlement exceeds a permissible/safe limit. Moreover, using the present approach, the track performance can be enhanced by optimizing the substructure layer parameters.

\section{ASSUMPTIONS, LIMITATIONS AND FUTURE SCOPE}

The main assumptions in the proposed method are:

- The distribution of vertical load from the sleeper to the substructure layers is pyramidal

- No-slip condition exists for the ballast-capping and capping-subgrade interfaces

- The track structure is symmetric with respect to the track centerline

- The substructure layer overlays the bedrock 
The limitations of the present approach are as follows:

- Principal stress rotation: The present approach neglects the influence of principal stress rotation on the track response. The rotation of principal stress can affect the irrecoverable deformations of the geomaterials (Gräbe and Clayton 2009).

- Vehicle-track interaction: In the present study, a dynamic amplification factor has been employed to account for the additional loads applied on the track due to vehicle-track interaction, which is a simplified approach.

- Loading direction: The present approach considers loading only along the vertical direction. However, in reality, the track is subjected to a combination of loads along the vertical, lateral and longitudinal directions (Esveld 2001).

The future investigations shall address these limitations to improve the accuracy of the present approach.

\section{CONCLUSIONS}

This article presents an integrated approach to evaluate the recoverable and irrecoverable responses of the substructure layers in ballasted railway tracks. The track substructure layers have been represented as lumped masses connected by springs and dashpots, which accounts for the discrete sleeper support. The key features of the present approach include:

- consideration of more appropriate inclusion of three substructure layers (ballast, capping and subgrade), compared to the existing models simplifying track substructure as single or dual layers.

- incorporation of overlapping of the load distribution pyramids along both transverse and longitudinal directions, which is an improvement over the existing models.

- prediction of irrecoverable deformation in ballast, capping and subgrade layers using empirical settlement models for individual layers. 
451 A good agreement between the responses predicted using the present method and the field investigations reported in the literature clearly indicates that the model can accurately predict the behavior of track substructure layers. The parametric investigation reveals that the irrecoverable deformation in the substructure layers is sensitive to the elastic modulus and thickness of individual layers. The response of each track layer is affected by the adjacent layers and the incorporation of multi-layered track structure enables more accurate prediction of track behavior. The proposed method is simple, computationally efficient and can be used readily as a tool by practicing engineers to optimize the track performance.

\section{Appendix I. Stress calculations}

The vertical stress in the ballast, capping and subgrade at any depth can be calculated using Eqs. (26), (27) and (28), respectively.

$$
\begin{gathered}
\sigma_{\mathrm{z}, \mathrm{b}}^{\prime}(t)=\frac{f_{\mathrm{b}, \mathrm{n}}(t)}{A_{\mathrm{b}}(z)} \\
\sigma_{\mathrm{z}, \mathrm{c}}^{\prime}(t)=\frac{c_{\mathrm{b}}\left[\dot{y}_{\mathrm{b}, \mathrm{n}}(t)-\dot{y}_{\mathrm{c}, \mathrm{n}}(t)\right]+k_{\mathrm{b}}\left[y_{\mathrm{b}, \mathrm{n}}(t)-y_{\mathrm{c}, \mathrm{n}}(t)\right]}{A_{\mathrm{c}}(\mathrm{z})} \\
\sigma_{\mathrm{z}, \mathrm{S}}^{\prime}(t)=\frac{c_{\mathrm{c}}\left[\dot{y}_{\mathrm{c}, \mathrm{n}}(t)-\dot{y}_{\mathrm{s}, \mathrm{n}}(t)\right]+k_{\mathrm{c}}\left[y_{\mathrm{c}, \mathrm{n}}(t)-y_{\mathrm{s}, \mathrm{n}}(t)\right]}{A_{\mathrm{s}}(z)}
\end{gathered}
$$

where $\sigma_{\mathrm{z}, \mathrm{b}}^{\prime}(t), \sigma_{\mathrm{z,c}}^{\prime}(t)$ and $\sigma_{\mathrm{z, \textrm {s }}}^{\prime}(t)$ are the vertical stresses $\left(\mathrm{N} / \mathrm{m}^{2}\right)$ in the ballast, capping and subgrade layers, respectively at depth $z$ and time $t ; A_{\mathrm{b}}(z), A_{\mathrm{c}}(z)$ and $A_{\mathrm{s}}(z)$ are the equivalent area $\left(\mathrm{m}^{2}\right)$ of ballast, capping and subgrade layers at depth $z$, respectively (refer to Fig. 4). The lateral stresses $\left(\sigma_{\mathrm{x}}^{\prime}, \sigma_{\mathrm{y}}^{\prime}\right)$ for each layer are calculated by multiplying the vertical stress with the coefficient of lateral earth pressure $\left[k_{0},\left(k_{0}=1-\sin \varphi^{\prime}\right.\right.$; where $\varphi^{\prime}=$ friction angle $\left.)\right]$. The average shear stress acting at each substructure layer can be evaluated as: 


$$
\begin{aligned}
\boldsymbol{T}_{n}^{s}= & 0.5\left[\begin{array}{ccc}
\frac{k_{\mathrm{s}}^{s}}{A_{\mathrm{s}}^{s}} & 0 & 0 \\
0 & \frac{k_{\mathrm{c}}^{s}}{A_{\mathrm{c}}^{s}} & 0 \\
0 & 0 & \frac{k_{\mathrm{b}}^{s}}{A_{\mathrm{b}}^{s}}
\end{array}\right]\left\{\begin{array}{l}
y_{\mathrm{s}, \mathrm{n}-1}(t)+y_{\mathrm{s}, \mathrm{n}+1}(t)-2 y_{\mathrm{s}, \mathrm{n}}(t) \\
y_{\mathrm{c}, \mathrm{n}-1}(t)+y_{\mathrm{c}, \mathrm{n}+1}(t)-2 y_{\mathrm{c}, \mathrm{n}}(t) \\
y_{\mathrm{b}, \mathrm{n}-1}(t)+y_{\mathrm{b}, \mathrm{n}+1}(t)-2 y_{\mathrm{b}, \mathrm{n}}(t)
\end{array}\right\} \\
+ & 0.5\left[\begin{array}{ccc}
\frac{c_{\mathrm{s}}^{s}}{A_{\mathrm{s}}^{s}} & 0 & 0 \\
0 & \frac{c_{\mathrm{c}}^{s}}{A_{\mathrm{c}}^{s}} & 0 \\
0 & 0 & \frac{c_{\mathrm{b}}^{s}}{A_{\mathrm{b}}^{s}}
\end{array}\right]\left\{\begin{array}{l}
\dot{y}_{s, \mathrm{n}-1}(t)+\dot{y}_{\mathrm{s}, \mathrm{n}+1}(t)-2 \dot{y}_{\mathrm{s}, \mathrm{n}}(t) \\
\dot{y}_{\mathrm{c}, \mathrm{n}-1}(t)+\dot{y}_{\mathrm{c}, \mathrm{n}+1}(t)-2 \dot{y}_{\mathrm{c}, \mathrm{n}}(t) \\
\dot{y}_{\mathrm{b}, \mathrm{n}-1}(t)+\dot{y}_{\mathrm{b}, \mathrm{n}+1}(t)-2 \dot{y}_{\mathrm{b}, \mathrm{n}}(t)
\end{array}\right\}
\end{aligned}
$$

where $\boldsymbol{T}_{\mathbf{n}} \mathrm{s}$ is the average shear stress vector at $n^{\text {th }}$ sleeper point in $y z$ plane; $A^{s}{ }_{\mathrm{b}}, A^{s}{ }_{\mathrm{c}}$ and $A^{s}$ s are the equivalent shear area $\left(\mathrm{m}^{2}\right)$ of ballast, capping and subgrade layers, respectively. The shear stress is assumed to be uniformly distributed along the entire thickness of the individual substructure layers. Fig. 4 shows the equivalent normal and shear area of the substructure layers considered in the present method. The equations to evaluate the octahedral normal and shear stresses, and deviator stress can be found in Timoshenko and Goodier (1970).

\section{Appendix II. Calculation of mass and stiffness of substructure layers}

The mass of the effective region of the substructure layers is calculated by multiplying the density of each layer with its volume. Figs. 10(a), (b) and (c) show the effective portion of ballast, capping and subgrade layers, respectively, in the case of no overlapping. Consider a small element $d z$ at a depth $z$ from the top of the ballast layer. The area of the element $\left[A_{\mathrm{b}}(\mathrm{z})\right]$ is given by:

$$
A_{\mathrm{b}}(z)=\left(b_{\mathrm{sl}}+2 z \tan \alpha\right)\left(l_{\mathrm{e}}+2 z \tan \alpha\right)
$$

The mass of this element is calculated as:

$$
d m_{\mathrm{b}}=\rho_{\mathrm{b}}\left(b_{\mathrm{sl}}+2 z \tan \alpha\right)\left(l_{\mathrm{e}}+2 z \tan \alpha\right) d z
$$

The mass of the total effective region of ballast can then be calculated by integrating Eq. (31):

$$
m_{\mathrm{b}}=\rho_{\mathrm{b}} \int_{z=0}^{z=h_{\mathrm{b}}}\left(b_{\mathrm{sl}}+2 z \tan \alpha\right)\left(l_{\mathrm{e}}+2 z \tan \alpha\right) d z
$$

Similarly, the mass of capping and subgrade layers can be determined as: 


$$
\begin{aligned}
m_{\mathrm{c}}=\rho_{\mathrm{c}} \int_{z=0}^{z=h_{\mathrm{c}}}\left(b_{\mathrm{sl}}+2 h_{\mathrm{b}} \tan \alpha+2 z \tan \beta\right)\left(l_{\mathrm{e}}+2 h_{\mathrm{b}} \tan \alpha+2 z \tan \beta\right) d z \\
m_{\mathrm{s}}=\rho_{\mathrm{s}} \int_{z=0}^{z=h_{\mathrm{s}}}\left(b_{\mathrm{sl}}+2 h_{\mathrm{b}} \tan \alpha+2 h_{\mathrm{c}} \tan \beta+2 z \tan \gamma\right)\left(l_{\mathrm{e}}+2 h_{\mathrm{b}} \tan \alpha+2 h_{\mathrm{c}} \tan \beta\right. \\
+2 z \tan \gamma) d z
\end{aligned}
$$

The stiffness of ballast, capping and subgrade layers is calculated using the analogy between effective region of substructure layers and an axially loaded bar with variable cross sectional area as:

$$
\begin{gathered}
k_{\mathrm{b}}=\frac{E_{\mathrm{b}}}{\int \frac{d z}{A_{\mathrm{b}}(z)}}=E_{\mathrm{b}}\left[\int_{z=0}^{z=h_{\mathrm{b}}} \frac{d z}{\left(b_{\mathrm{sl}}+2 z \tan \alpha\right)\left(l_{\mathrm{e}}+2 z \tan \alpha\right)}\right]^{-1} \\
k_{\mathrm{c}}=E_{\mathrm{c}}\left[\int_{z=0}^{z=h_{\mathrm{c}}} \frac{d z}{\left(b_{\mathrm{sl}}+2 h_{\mathrm{b}} \tan \alpha+2 z \tan \beta\right)\left(l_{\mathrm{e}}+2 h_{\mathrm{b}} \tan \alpha+2 z \tan \beta\right)}\right]^{-1} \\
k_{\mathrm{s}}=E_{\mathrm{s}}\left[\int_{z=0}^{z=h_{\mathrm{s}}} \frac{d z}{\left(b_{\mathrm{sl}}+2 h_{\mathrm{b}} \tan \alpha+2 h_{\mathrm{c}} \tan \beta+2 z \tan \gamma\right)\left(l_{\mathrm{e}}+2 h_{\mathrm{b}} \tan \alpha+2 h_{\mathrm{c}} \tan \beta+2 z \tan \gamma\right)}\right]^{-1}
\end{gathered}
$$

A similar procedure is employed to evaluate the mass and stiffness of the substructure layers in case of overlapping along the longitudinal and transverse directions.

\section{DATA AVAILABILITY STATEMENT}

Some or all data, models, or code that support the findings of this study are available from the corresponding author upon reasonable request.

\section{ACKNOWLEDGMENTS}

This research is financially supported by an Australian Government Research Training Program Scholarship. This support is gratefully acknowledged. 


\section{Notation}

The following symbols are used in this paper:

$a, m, b=$ empirical parameters that depend on the type of subgrade soil;

$A_{\mathrm{b}}(z), A_{\mathrm{c}}(z), A_{\mathrm{s}}(z)=$ equivalent area of ballast, capping and subgrade layers at depth $z$, respectively $\left(\mathrm{m}^{2}\right)$; $A_{\mathrm{b}}^{s}, A_{\mathrm{c}}^{s}, A_{\mathrm{s}}^{s}=$ equivalent shear area of ballast, capping and subgrade layers, respectively $\left(\mathrm{m}^{2}\right)$;

$a_{\mathrm{t}}=$ total number of wheels/axles under consideration;

$b_{\mathrm{sl}}=$ width of sleeper $(\mathrm{m})$;

$c_{\mathrm{b}}, c_{\mathrm{c}}, c_{\mathrm{s}}=$ damping coefficients of ballast, capping and subgrade, respectively (Ns/m); $c_{\mathrm{b}}^{s}, c_{{ }_{\mathrm{c}}}^{s}, c_{\mathrm{s}}^{s}=$ shear damping coefficients of ballast, capping and subgrade, respectively (Ns/m); $D_{\mathrm{w}}=$ wheel diameter $(\mathrm{m})$;

$E_{\mathrm{r}}, E_{\mathrm{b}}, E_{\mathrm{c}}, E_{\mathrm{s}}=$ elastic modulus of rail, ballast, capping and subgrade, respectively $\left(\mathrm{N} / \mathrm{m}^{2}\right)$; $f_{\mathrm{s}, \mathrm{n}}, f_{\mathrm{c}, \mathrm{n}}, f_{\mathrm{b}, \mathrm{n}}=$ external forces acting on the subgrade, capping and ballast, respectively $(\mathrm{N})$;

$g_{\mathrm{t}}=$ centre-to-centre distance between the rails (m); $h_{\mathrm{b}}, h_{\mathrm{c}}, h_{\mathrm{s}}=$ thickness of ballast, capping and subgrade, respectively (m);

$h_{\mathrm{bl}}, h_{\mathrm{bt}}=$ overlap height in ballast along longitudinal and transverse direction, respectively (m);

$h_{\mathrm{cl}} h_{\mathrm{ct}}=$ overlap height in capping along longitudinal and transverse direction, respectively (m);

$h_{\mathrm{i}}=$ thickness of $i^{\text {th }}$ subgrade layer (m);

$h_{\mathrm{sl}}, h_{\mathrm{st}}=$ overlap height in subgrade along longitudinal and transverse direction, respectively (m);

$I=$ moment of inertia of rail $\left(\mathrm{m}^{4}\right)$;

$i_{1}, i_{2}=$ empirical parameters that depend on the axle load and subgrade type;

$k=$ track modulus $\left(\mathrm{N} / \mathrm{m}^{2}\right)$;

$k_{0}=$ coefficient of lateral earth pressure;

$k_{1}^{b}, k_{2}{ }^{b}, k_{3}{ }^{b}, k_{4}{ }^{b}=$ empirical parameters for ballast;

$k_{1}^{c}, k_{2}{ }^{c}, k_{3}{ }^{c}, k_{4}{ }^{c}=$ empirical parameters for capping;

$k_{\mathrm{b}}, k_{\mathrm{c}}, k_{\mathrm{s}}=$ stiffness of ballast, capping and subgrade, respectively $(\mathrm{N} / \mathrm{m})$;

$k_{\mathrm{p}}=$ spring constant of rail pad (including sleeper) $(\mathrm{N} / \mathrm{m})$;

$k_{\mathrm{b}}^{\mathrm{s}}, k_{\mathrm{c}}^{\mathrm{s}} k_{\mathrm{s}}^{\mathrm{s}}=$ shear stiffness of ballast, capping and subgrade, respectively $(\mathrm{N} / \mathrm{m})$;

$L=$ characteristic length $(\mathrm{m})$;

$l_{\mathrm{e}}=$ effective length of sleeper $(\mathrm{m})$;

$l_{\mathrm{sl}}=$ length of sleeper $(\mathrm{m})$;

$m_{\mathrm{b}}, m_{\mathrm{c}}, m_{\mathrm{s}}=$ vibrating mass of ballast, capping and subgrade, respectively (kg);

$N=$ number of load cycles;

$P_{\text {atm }}=$ atmospheric pressure $\left(\mathrm{N} / \mathrm{m}^{2}\right)$;

$Q=$ static wheel load $(\mathrm{N})$;

$Q_{\mathrm{a}}=$ static axle load $(\mathrm{N})$;

$Q_{\mathrm{r}, \mathrm{n}}=$ rail seat load at $n^{\text {th }}$ sleeper $(\mathrm{N})$;

$S=$ sleeper spacing $(\mathrm{m})$;

$S_{\mathrm{s}}=$ total irrecoverable deformation in subgrade $(\mathrm{m})$;

$\boldsymbol{T}_{\mathbf{n}} \mathrm{s}=$ average shear stress vector at $n^{\text {th }}$ sleeper point in $y z$ plane;

$V=$ train speed $(\mathrm{m} / \mathrm{s})$;

$x_{\mathrm{nj}}=$ distance between the $n^{\text {th }}$ sleeper and $j^{\text {th }}$ wheel/axle (m);

$\ddot{y}_{\mathrm{b}, \mathrm{n}}, \dot{y}_{\mathrm{b}, \mathrm{n}} y_{\mathrm{b}, \mathrm{n}}=$ acceleration, velocity and displacement for ballast below $n^{\text {th }}$ sleeper, respectively;

$\ddot{y}_{\mathrm{c}, \mathrm{n}}, \dot{y}_{\mathrm{c}, \mathrm{n}}, y_{\mathrm{c}, \mathrm{n}}=$ acceleration, velocity and displacement for capping below $n^{\text {th }}$ sleeper, respectively; $\ddot{y}_{\mathrm{s}, \mathrm{n}}, \dot{y}_{\mathrm{s}, \mathrm{n}}$ and $y_{\mathrm{s}, \mathrm{n}}=$ acceleration, velocity and displacement of subgrade below $n^{\text {th }}$ sleeper, respectively;

$\alpha, \beta, \gamma=$ stress distribution angles for ballast, capping and subgrade, respectively $\left({ }^{\circ}\right)$; $\alpha_{0}, \beta_{0}=$ reference stress distribution angles for ballast and capping, respectively $\left({ }^{\circ}\right)$; 


\section{Supplemental Data (\#1 vibrating mass and stiffness of substructure layers)}

The equations to evaluate the mass and stiffness of the substructure layers for different cases of overlapping will be provided by the corresponding author upon request.

\section{REFERENCES}

Ahlbeck, D. R., Meacham, H. C., and Prause, R. H. (1975). "The development of analytical models for railroad track dynamics." Symp. on Railroad Track Mechanics, Pergamon Press, Princeton University, 239-263.

Banimahd, M., Woodward, P., Kennedy, J., and Medero, G. (2013). "Three-dimensional modelling of high speed ballasted railway tracks." Proc. Inst. Civ. Eng. Transp., 166(2), 113-123.

Basu, D., and Kameswara Rao, N. S. V. (2013). "Analytical solutions for Euler-Bernoulli beam on visco-elastic foundation subjected to moving load." Int. J. Numer. Anal. Methods Geomech., 37(8), 945-960.

Bian, X., Jiang, H., and Chen, Y. (2010). "Accumulative deformation in railway track induced by high-speed traffic loading of the trains." Earthq. Eng. Eng. Vib., 9(3), 319-326.

Burmister, D. (1958). "Evaluation of pavement systems of the WASHO road test by layered system methods." Highway Research Board Bulletin, 177, $26-54$.

Chen, J., and Zhou, Y. (2018). "Dynamic responses of subgrade under double-line high-speed railway." Soil Dyn. Earthquake Eng., 110, 1-12.

Chen, Y. H., and Huang, Y. H. (2000). "Dynamic stiffness of infinite Timoshenko beam on viscoelastic foundation in moving co- ordinate." Int. J. Numer. Methods Eng., 48(1), $1-18$. 
Choudhury, D., Bharti, R. K., Chauhan, S., and Indraratna, B. (2008). "Response of multilayer foundation system beneath railway track under cyclic loading." J. Geotech Geoenviron. Eng., 134(10), 1558-1563.

Connolly, D., Giannopoulos, A., and Forde, M. (2013). "Numerical modelling of ground borne vibrations from high speed rail lines on embankments." Soil Dyn. Earthquake Eng., 46, $13-19$.

Costa, P., Calçada, R., Cardoso, A., and Bodare, A. (2010). "Influence of soil non-linearity on the dynamic response of high-speed railway tracks." Soil Dyn. Earthquake Eng., 30(4), $221-235$.

Dieterman, H., and Metrikine, V. (1997). "Steady-state displacements of a beam on an elastic half-space due to a uniformly moving constant load." Eur. J. Mech. A. Solids, 16(2), 295-306.

Doyle, N. F. (1980). "Railway track design a review of current practice." B. o. T. Economics, ed., Australian government publishing service, Canberra.

Esveld, C. (2001). Modern railway track, MRT-Productions, Delft, The Netherlands.

Galvín, P., Mendoza, D., Connolly, D., Degrande, G., Lombaert, G., and Romero, A. (2018). "Scoping assessment of free-field vibrations due to railway traffic." Soil Dyn. Earthquake Eng., 114, 598-614.

Galvín, P., Romero, A., and Domínguez, J. (2010). "Fully three-dimensional analysis of highspeed train-track-soil-structure dynamic interaction." J. Sound Vib., 329(24), 51475163.

Giroud, J., and Han, J. (2004). "Design method for geogrid-reinforced unpaved roads. I. Development of design method." J. Geotech. Geoenviron. Eng., 130(8), 776-786.

Gräbe, P., Clayton, C., and Shaw, F. (2005). "Deformation measurement on a heavy haul track formation." 8th International Heavy Haul Conference, International Heavy Haul Association, Rio de Janeiro, Brazil.

Gräbe, P., and Shaw, F. (2010). "Design life prediction of a heavy haul track foundation." Proc Inst Mech Eng F Rail Rapid Transit 224(5), 337-344.

Gräbe, P. J., and Clayton , C. R. I. (2009). "Effects of Principal Stress Rotation on Permanent Deformation in Rail Track Foundations." Journal of Geotechnical and Geoenvironmental Engineering, 135(4), 555-565.

Guo, Y., and Zhai, W. (2018). "Long-term prediction of track geometry degradation in highspeed vehicle-ballastless track system due to differential subgrade settlement." Soil Dyn. Earthquake Eng., 113, 1-11. 
Hall, L. (2003). "Simulations and analyses of train-induced ground vibrations in finite element models." Soil Dyn. Earthquake Eng., 23(5), 403-413.

Han, J., Acharya, R., Parsons, R., and Khatri, D. (2013). "Improved load distribution for load rating of low-fill box structures." K-TRAN: KU12-3, Kansas Department of Transportation.

Hung, H., Chen, G., and Yang, Y. (2013). "Effect of railway roughness on soil vibrations due to moving trains by 2.5 D finite/infinite element approach." Eng. Struct., 57, 254-266.

Karlström, A., and Boström, A. (2006). "An analytical model for train-induced ground vibrations from railways." J. Sound Vib., 292(1-2), 221-241.

Kaynia, A. M., Madshus, C., and Zackrisson, P. (2000). "Ground vibration from high-speed trains: Prediction and countermeasure." J. Geotech. Geoenviron. Eng., 126(6), 531-537.

Kuo, C. M., and Huang, C. H. (2009). "Two approaches of finite-element modeling of ballasted railway track." J. Geotech. Geoenviron. Eng., 135(3), 455-458.

Li, D., Hyslip, J., Sussmann, T., and Chrismer, S. (2016). Railway geotechnics, Taylor and Francis, Boca Raton, USA.

Li, D., and Selig, E. T. (1996). "Cumulative plastic deformation for fine-grained subgrade soils." Journal of Geotechnical Engineering 122(12), 1006-1013.

Li, D., and Selig, E. T. (1998). "Method for railroad track foundation design. I: Development." Journal of Geotechnical Engineering, 124(4), 316-322.

Li, L., Nimbalkar, S., and Zhong, R. (2018). "Finite element model of ballasted railway with infinite boundaries considering effects of moving train loads and Rayleigh waves." Soil Dyn. Earthquake Eng., 114, 147-153.

Metrikine, A. V., and Popp, K. (1999). "Vibration of a periodically supported beam on an elastic half-space." Eur. J. Mech. A. Solids, 18(4), 679-701.

Mishra, D., Qian, Y., Huang, H., and Tutumluer, E. (2014). "An integrated approach to dynamic analysis of railroad track transitions behavior." Transp. Geotech., 1(4), 188200.

Nguyen, K., Villalmanzo, D., Goicolea, J., and Gabaldon, F. (2016). "A computational procedure for prediction of ballasted track profile degradation under railway traffic loading." Proc Inst Mech Eng F J Rail Rapid Transit, 230(8), 1812-1827.

Nimbalkar, S., and Indraratna, B. (2016). "Improved performance of ballasted rail track using geosynthetics and rubber shockmat." J. Geotech. Geoenviron. Eng., 142(8). 
Nimbalkar, S., Indraratna, B., Dash, S. K., and Christie, D. (2012). "Improved Performance of Railway Ballast under Impact Loads Using Shock Mats." Journal of Geotechnical and Geoenvironmental Engineering, 138(3), 281-294.

Oscarsson, J., and Dahlberg, T. (1998). "Dynamic train/track/ballast interaction - computer models and full-scale experiments." Veh. Syst. Dyn., 29(S1), 73-84.

Powrie, W., Yang, L. A., and Clayton, C. R. I. (2007). "Stress changes in the ground below ballasted railway track during train passage." Proc. Inst. Mech. Eng. F. J. Rail Rapid Transit 221(F2), 247-262.

Priest, J. A., Powrie, W., Yang, L., Grabe, P. J., and Clayton, C. R. I. (2010). "Measurements of transient ground movements below a ballasted railway line." Géotechnique, 60(9), 667-677.

Punetha, P., Nimbalkar, S., and Khabbaz, H. (2019). "Evaluation of additional confinement for three-dimensional geoinclusions under general stress state." Can. Geotech. J.

Sayeed, M. A., and Shahin, M. A. (2016). "Three-dimensional numerical modelling of ballasted railway track foundations for high-speed trains with special reference to critical speed." Transp. Geotech., 6, 55-65.

Selig, E. T., and Waters, J. M. (1994). Track geotechnology and substructure management, Thomas Telford, London.

Shahu, J., Kameswara Rao, N., and Yudhbir (1999). "Parametric study of resilient response of tracks with a sub-ballast layer." Can. Geotech. J., 36(6), 1137-1150.

Sheng, X., Jones, C. J. C., and Petyt, M. (1999). "Ground vibration generated by a harmonic load acting on a railway track." J. Sound Vib., 225(1), 3-28.

Stewart, H., and Selig, E. (1982). "Predicted and measured resilient response of track." Journal of Geotechnical Engineering Division, 108(11), 1423-1442.

Suiker, A. S. J., and De Borst, R. (2003). "A numerical model for the cyclic deterioration of railway tracks." Int. J. Numer. Methods Eng., 57(4), 441-470.

Suiker, A. S. J., Selig, E. T., and Frenkel, R. (2005). "Static and cyclic triaxial testing of ballast and subballast." J. Geotech. Geoenviron. Eng., 131(6), 771-782.

Sun, Q. D., Indraratna, B., and Nimbalkar, S. (2016). "Deformation and degradation mechanisms of railway ballast under high frequency cyclic loading." J. Geotech. Geoenviron. Eng., 142(1).

Sun, Y. Q., and Dhanasekar, M. (2002). "A dynamic model for the vertical interaction of the rail track and wagon system." Int. J. Solids Struct., 39(5), 1337-1359. 
Takemiya, H., and Bian, X. (2005). "Substructure simulation of inhomogeneous track and layered ground dynamic interaction under train passage." J. Eng. Mech., 131(7), 699711.

Timoshenko, S. P., and Goodier, J. N. (1970). Theory of elasticity, McGraw Hill, New York.

Yang, L. A., Powrie, W., and Priest, J. A. (2009). "Dynamic stress analysis of a ballasted railway track bed during train passage." J. Geotech. Geoenviron. Eng., 135(5), 680689.

Yang, Y. B., and Hung, H. H. (2001). "A 2.5D finite/infinite element approach for modelling visco- elastic bodies subjected to moving loads." Int. J. Numer. Methods Eng., 51(11), 1317-1336.

Zhai, W., Wang, K., and Cai, C. (2009). "Fundamentals of vehicle-track coupled dynamics." Veh. Syst. Dyn., 47(11), 1349-1376.

Zhai, W. M., Wang, K. Y., and Lin, J. H. (2004). "Modelling and experiment of railway ballast vibrations." J. Sound Vib., 270(4-5), 673-683.

Zhang, T. W., Cui, Y. J., Lamas-Lopez, F., Calon, N., and Costa D’Aguiar, S. (2016). "Modelling stress distribution in substructure of French conventional railway tracks." Constr. Build. Mater., 116, 326-334. 
TABLES

Table 1. Parameters $a, b$ and $m$ for different subgrade soils [adapted from (Li and Selig 1996)]

\begin{tabular}{lccc}
\hline Subgrade soil type & $a$ & $b$ & $m$ \\
\hline ML (silt) & 0.64 & $0.06-0.17$ & $1.4-2.0$ \\
MH (silt of high plasticity) & 0.84 & $0.08-0.19$ & $1.3-4.2$ \\
CL (clay of low plasticity) & $0.30-3.5$ & $0.08-0.34$ & $1.0-2.6$ \\
CH (clay of high plasticity) & $0.82-1.5$ & $0.12-0.27$ & $1.3-3.9$ \\
\hline
\end{tabular}

Table 2. Parameters used for evaluation of track response

\begin{tabular}{|c|c|c|c|c|c|c|c|}
\hline Variable & Symbol & Unit & $\begin{array}{c}\text { Takemiya } \\
\text { and Bian } \\
(2005)\end{array}$ & $\begin{array}{l}\text { Gräbe et al. } \\
(2005) ; \\
\text { Gräbe and } \\
\text { Shaw (2010) }\end{array}$ & $\begin{array}{c}\text { Priest et } \\
\text { al. } \\
(2010)\end{array}$ & $\begin{array}{l}\text { Mishra et } \\
\text { al. (2014) }\end{array}$ & Present study \\
\hline \multicolumn{8}{|l|}{$\overline{\text { Ballast (Top layer) }}$} \\
\hline Elastic modulus & $E_{\mathrm{b}}$ & $\mathrm{MPa}$ & 23 & 80 & 80 & 69 & $138-551(276)$ \\
\hline Poisson's ratio & $v_{\mathrm{b}}$ & - & 0.45 & 0.3 & 0.3 & 0.3 & 0.3 \\
\hline Shear stiffness & $k_{\mathrm{b}}{ }^{\mathrm{s}}$ & $\mathrm{MN} / \mathrm{m}$ & 1 & 0.1 & 0.1 & 78.4 & 78.4 \\
\hline Shear damping & $\mathrm{Cb}_{\mathrm{b}}^{\mathrm{s}}$ & $\mathrm{kNs} / \mathrm{m}$ & 80 & 80 & 80 & 80 & 80 \\
\hline Density & $\rho_{\mathrm{b}}$ & $\mathrm{kg} / \mathrm{m}^{3}$ & 1,500 & 1,800 & 1,800 & 1,990 & 1,760 \\
\hline Thickness & $h_{\mathrm{b}}$ & $\mathrm{m}$ & 1 & 0.3 & 0.3 & 0.305 & $0.15-0.6(0.3)$ \\
\hline \multicolumn{8}{|c|}{ Capping (Middle layer) } \\
\hline Elastic modulus & $E_{\mathrm{c}}$ & $\mathrm{MPa}$ & 6 & 140 & 140 & 55 & $69-276(138)$ \\
\hline Poisson's ratio & $v_{\mathrm{c}}$ & - & 0.45 & 0.3 & 0.3 & 0.4 & 0.35 \\
\hline Shear stiffness & $k_{\mathrm{c}}^{\mathrm{s}}$ & $\mathrm{MN} / \mathrm{m}$ & 250 & 476 & 476 & 1,600 & 476 \\
\hline Shear damping & $c_{\mathrm{c}}^{\mathrm{s}}$ & $\mathrm{kNs} / \mathrm{m}$ & 800 & 80 & 80 & 80 & 80 \\
\hline Density & $\rho_{\mathrm{c}}$ & $\mathrm{kg} / \mathrm{m}^{3}$ & 1,260 & 2,300 & 2,300 & 2,092 & 1,920 \\
\hline Thickness & $h_{\mathrm{c}}$ & $\mathrm{m}$ & 3 & 0.8 & 0.8 & 0.127 & $0.15-0.45(0.15)$ \\
\hline \multicolumn{8}{|l|}{ Subgrade } \\
\hline Elastic modulus & $E_{\mathrm{s}}$ & $\mathrm{MPa}$ & 44 & 600 & 600 & 45 & $14-276(14)$ \\
\hline Poisson's ratio & $v_{\mathrm{s}}$ & - & 0.45 & 0.25 & 0.25 & 0.4 & 0.35 \\
\hline Shear stiffness & $k_{\mathrm{s}}^{\mathrm{s}}$ & $\mathrm{MN} / \mathrm{m}$ & 3,000 & 1,600 & 1,600 & 1,600 & 1,600 \\
\hline Shear damping & $c_{\mathrm{s}}^{\mathrm{s}}$ & $\mathrm{kNs} / \mathrm{m}$ & 800 & 80 & 80 & 80 & 80 \\
\hline Density & $\rho_{\mathrm{s}}$ & $\mathrm{kg} / \mathrm{m}^{3}$ & 1,475 & 2,300 & 2,300 & 2,092 & 1,920 \\
\hline Thickness & $h_{\mathrm{s}}$ & $\mathrm{m}$ & 44 & 3.29 & 3.29 & 2 & $1-10(4.5)$ \\
\hline
\end{tabular}

Note: The values of shear stiffness and damping have been calculated using a trial and error procedure. The initial values for the trial and error procedure, and the parametric study were chosen according to those reported by Zhai et al. (2004) and Oscarsson and Dahlberg (1998); empirical parameters for irrecoverable deformation are taken from Sun et al. (2016) and Suiker et al. (2005) for ballast and capping, respectively.

Table 3. Comparison of results reported by Gräbe et al. (2005) with model predictions

\begin{tabular}{lcccc}
\hline $\begin{array}{l}\text { Depth below } \\
\text { foundation } \\
(\mathrm{mm})\end{array}$ & \multicolumn{2}{c}{ Settlement $(\mathrm{mm})$} & \multicolumn{2}{c}{ Vertical stress $(\mathrm{kPa})$} \\
\cline { 2 - 5 } & $\begin{array}{c}\text { Gräbe et al. } \\
(2005)\end{array}$ & $\begin{array}{c}\text { Model } \\
\text { prediction }\end{array}$ & $\begin{array}{c}\text { Gräbe et al. } \\
(2005)\end{array}$ & $\begin{array}{c}\text { Model } \\
\text { prediction }\end{array}$ \\
\hline 0 & 0.54 & 0.51 & 110 & 84 \\
400 & - & - & 76 & 75 \\
800 & 0.23 & 0.18 & 59.6 & 53 \\
\hline
\end{tabular}


LIST OF FIGURES

707 Fig. 1(a). Configuration of Thalys high-speed train; (b). calculation of track deflection at time $708 t_{1} ;(\mathbf{c})$. calculation of track deflection at time $t_{2} ;(\mathbf{d})$. final rail seat load-time history

709 Fig. 2. Three degree of freedom mass-spring-dashpot (MSD) model of track

710 Fig. 3. Overlapping along longitudinal direction in (a). ballast; (b). capping; (c). subgrade; 711 transverse direction in (d). ballast; (e). capping; (f). subgrade

712 Fig. 4. Effective portion of substructure layers considered in analysis

713 Fig. 5. Comparison of vertical displacement and acceleration time histories predicted using the 714 present method with field results reported by Takemiya and Bian (2005)

715 Fig. 6. Comparison of model predictions with the field results reported by Gräbe and Shaw $716 \quad(2010)$

717 Fig. 7. Comparison of model predictions with results reported by Priest et al. (2010): (a). 718 resilient displacement for 26-tonne axle load coal wagons; (b). resilient displacement at different depth below the sleeper; (c). resilient displacement for 20-tonne axle load coal wagons (d). vertical stress at $800 \mathrm{~mm}$ below sleeper bottom

Fig. 8. Comparison of model predictions with field results reported by Mishra et al. (2014)

Fig. 9. Variation of average irrecoverable strain in substructure layers with (a). thickness; (b). elastic modulus

Fig. 10. Effective region of (a) ballast; (b) capping and (c) subgrade layers 


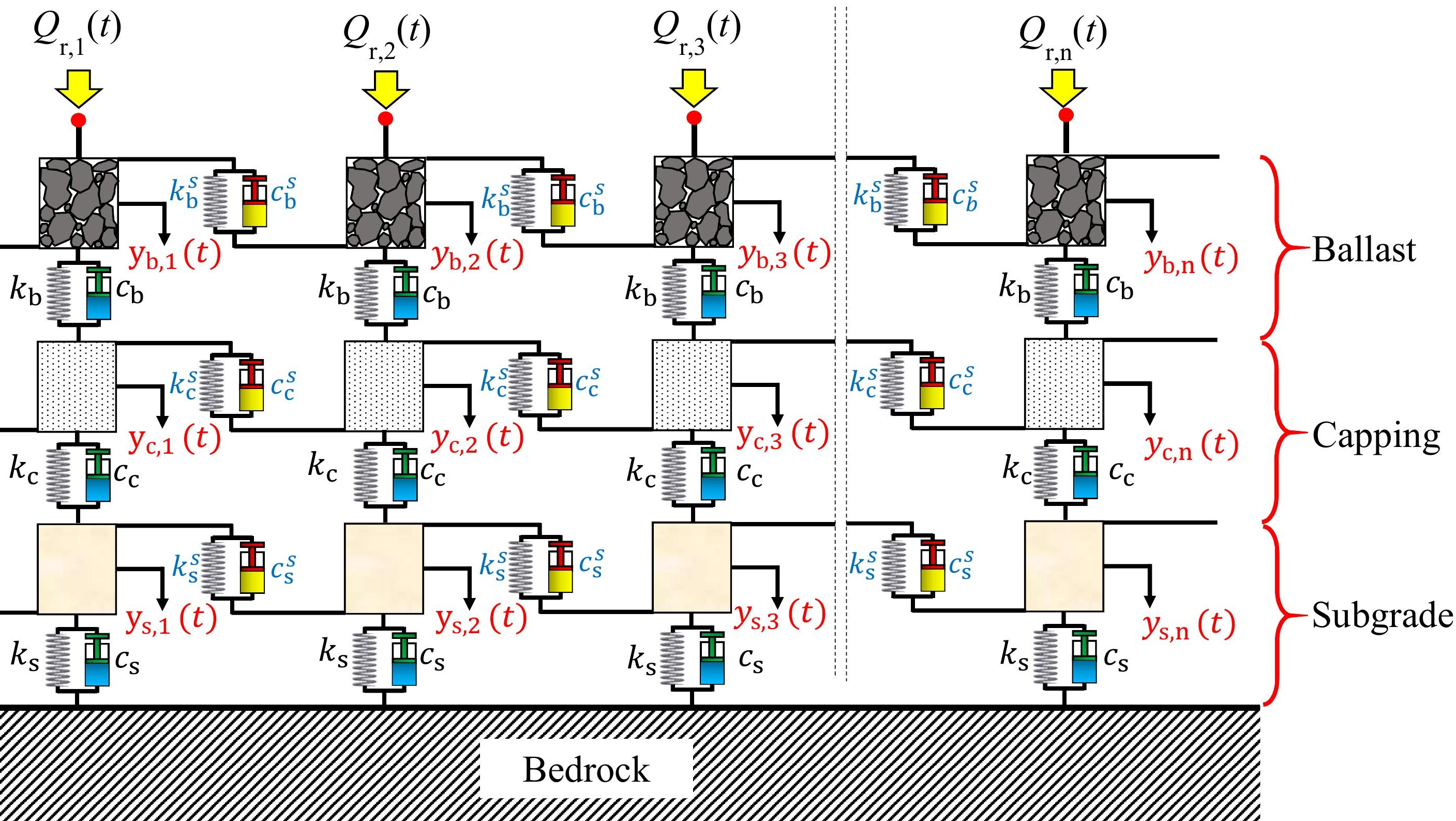




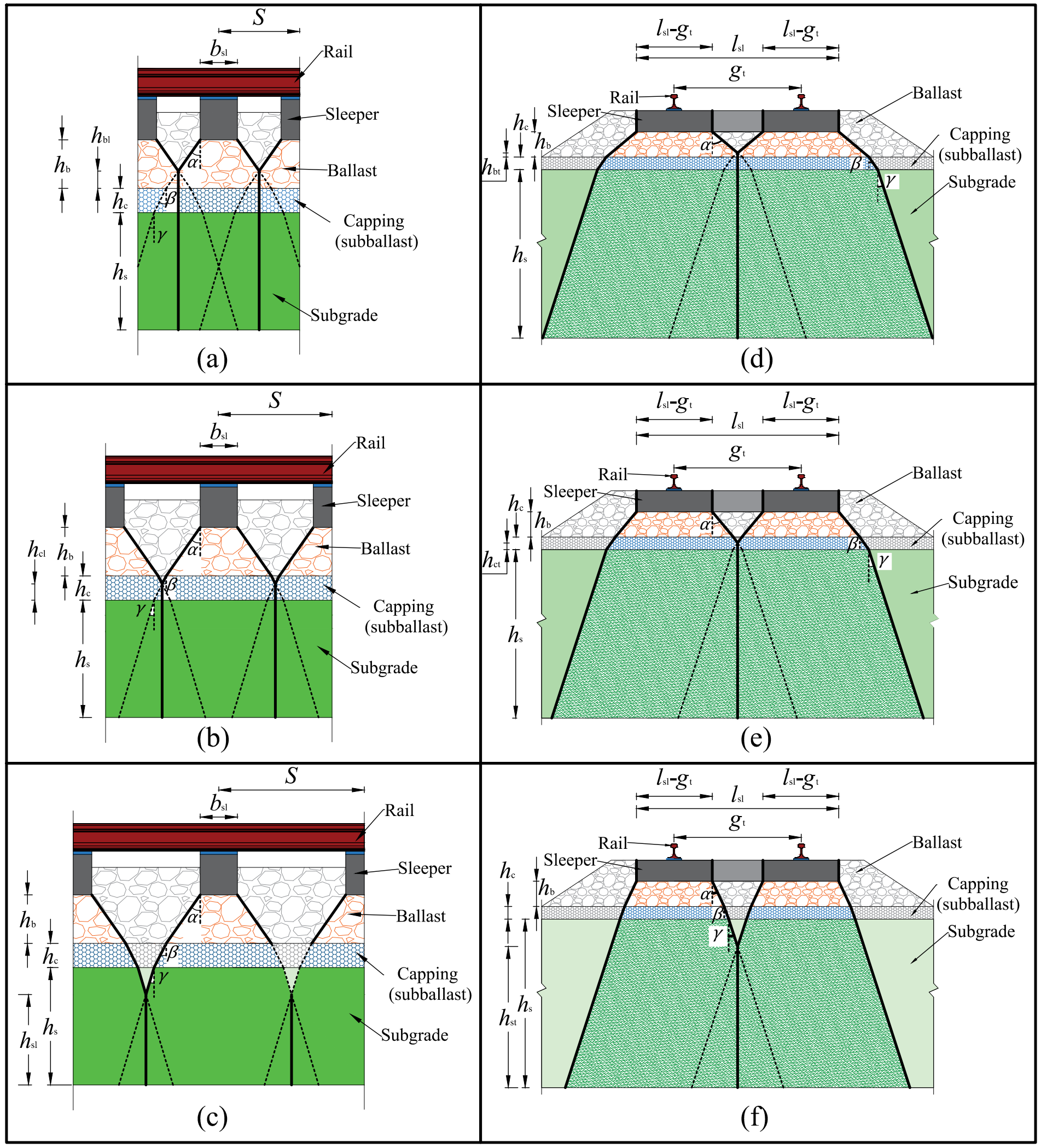


Click here to access/download;Figure;Figure_5.pdf $\stackrel{\underline{ }}{ }$
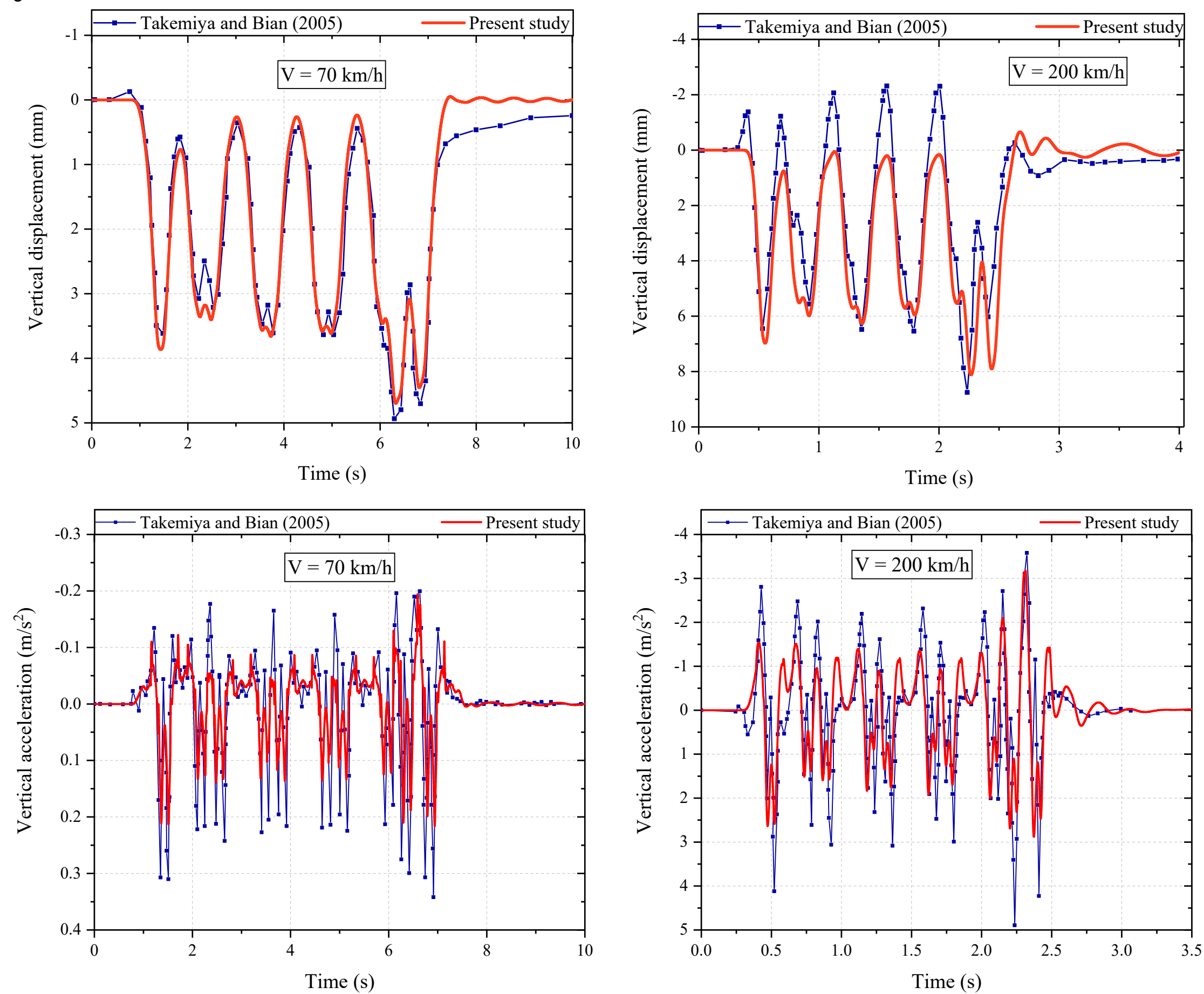

$D_{\mathrm{w}}=1.016 \mathrm{~m}$
$Q_{\mathrm{a}}=118-180 \mathrm{kN}$
$i_{1}=0.0065$
$i_{2}=1$
$g_{\mathrm{t}}=1.6 \mathrm{~m}$
$E_{\mathrm{r}}=207 \mathrm{GPa}$
$I=3.04 \times 10^{-5} \mathrm{~m}^{4}$
$b_{\mathrm{sl}}=0.4 \mathrm{~m}$
$l_{\mathrm{sl}}=3.1 \mathrm{~m}$
$S=0.65 \mathrm{~m}$
$k_{\mathrm{p}}=54 \mathrm{MN} / \mathrm{m}$
$\alpha_{0}=27^{\circ}$
$\beta_{0}=27^{\circ}$
$\gamma=27^{\circ}$




\section{Tonnage (MGT)}

Click here to access/download;Figure;Figure_6.pdf $\stackrel{\underline{ }}{ }$

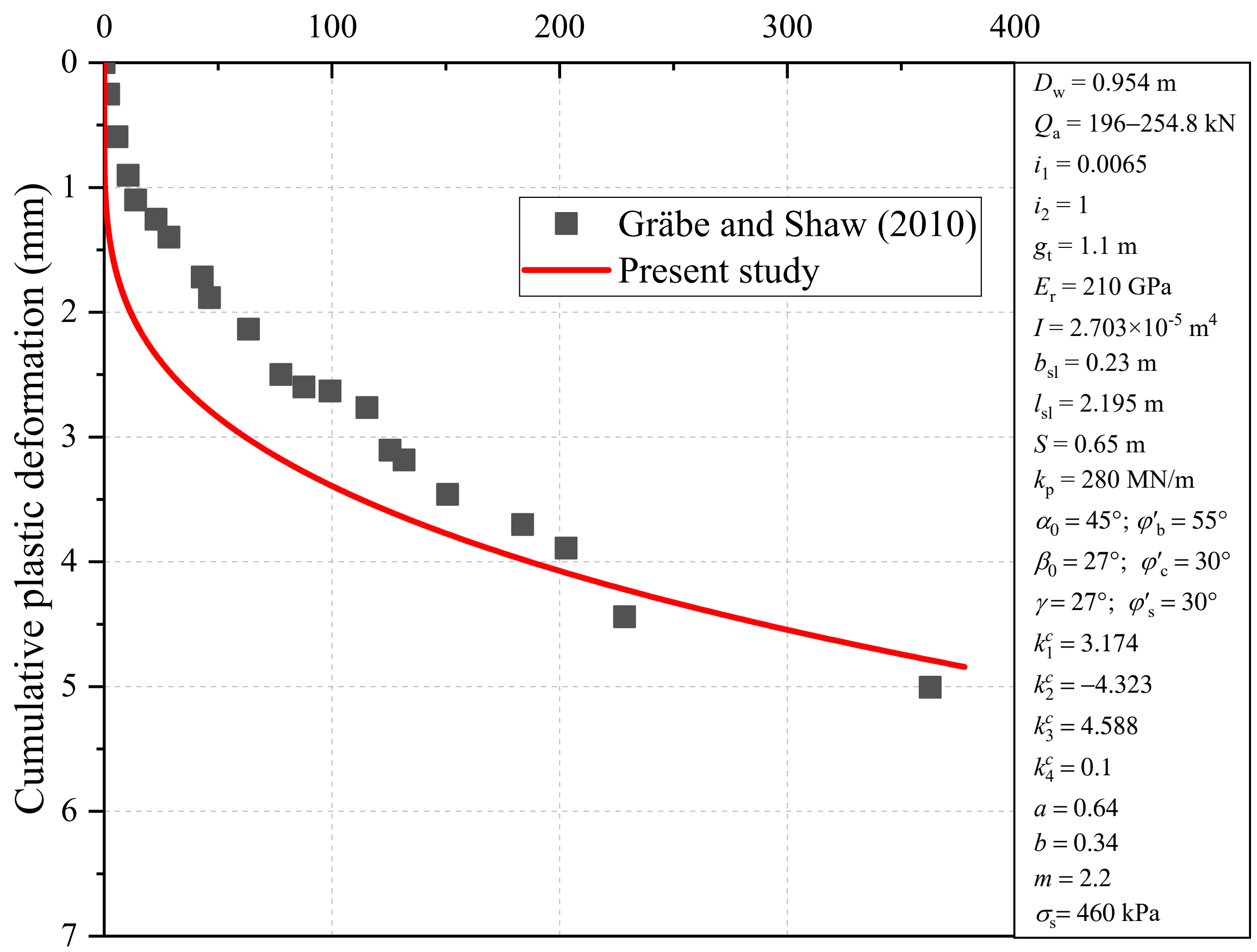




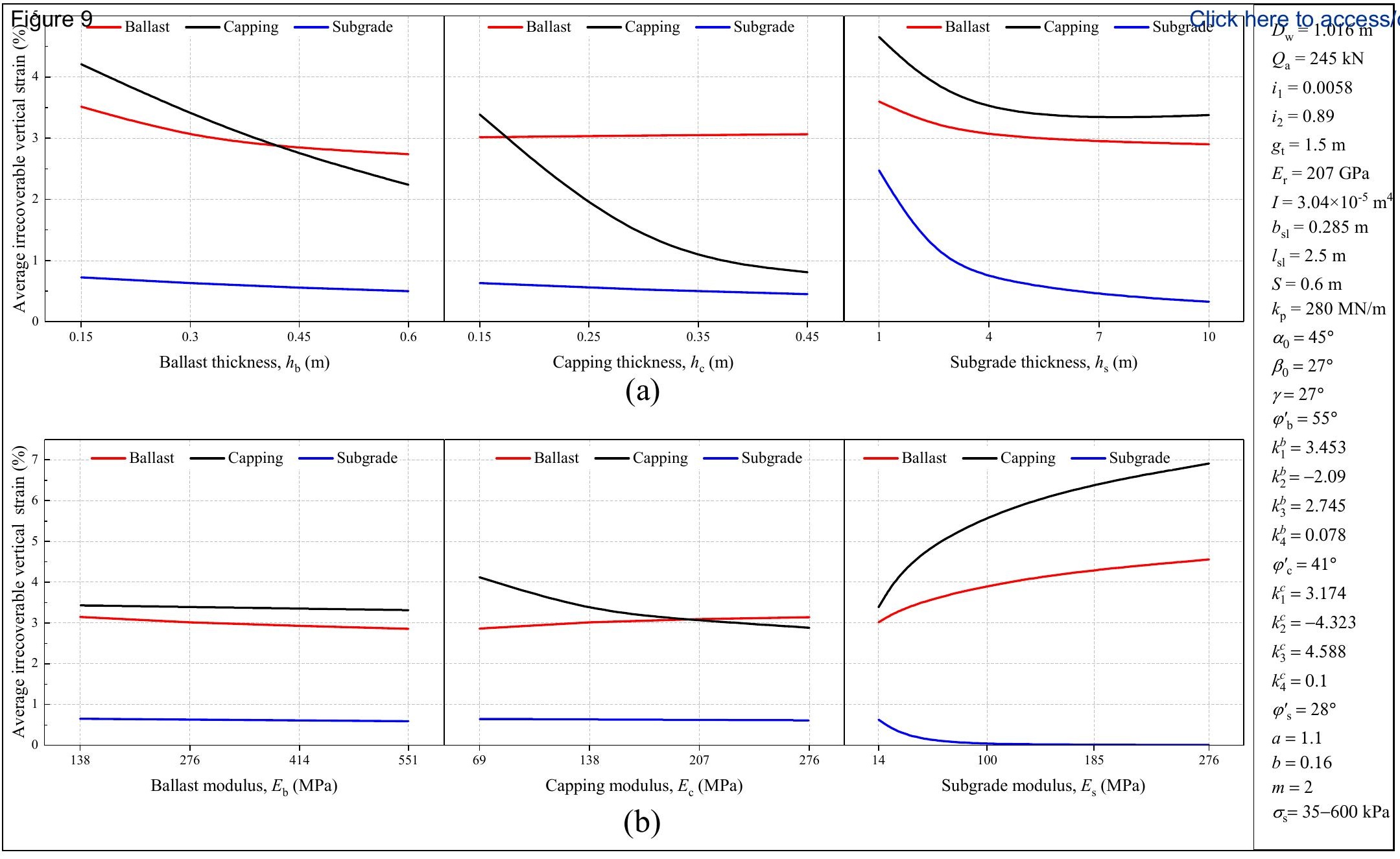




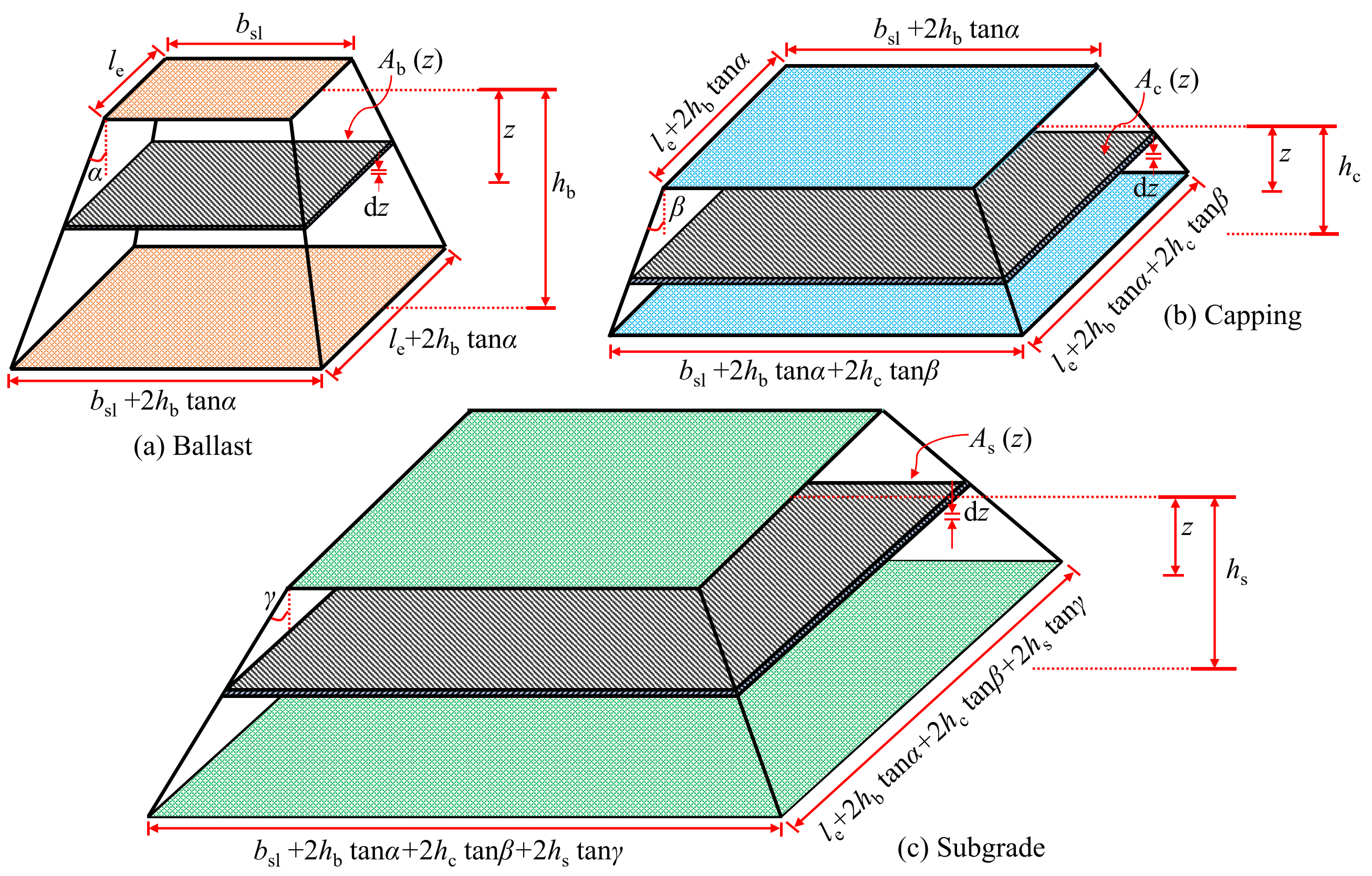

